This item was submitted to Loughborough's Research Repository by the author.

Items in Figshare are protected by copyright, with all rights reserved, unless otherwise indicated.

\title{
Gear teeth impacts in hydrodynamic conjunctions promoting idle gear rattle
}

PLEASE CITE THE PUBLISHED VERSION

http://dx.doi.org/10.1016/j.jsv.2007.01.034

PUBLISHER

(C) Elsevier

VERSION

AM (Accepted Manuscript)

PUBLISHER STATEMENT

This work is made available according to the conditions of the Creative Commons Attribution-NonCommercialNoDerivatives 4.0 International (CC BY-NC-ND 4.0) licence. Full details of this licence are available at: https://creativecommons.org/licenses/by-nc-nd/4.0/

\section{LICENCE}

CC BY-NC-ND 4.0

\section{REPOSITORY RECORD}

Theodossiades, Stephanos, Osman A.M. Tangasawi, and Homer Rahnejat. 2019. "Gear Teeth Impacts in Hydrodynamic Conjunctions Promoting Idle Gear Rattle”. figshare. https://hdl.handle.net/2134/18654. 


\title{
Gear Teeth Impacts in Hydrodynamic Conjunctions promoting
}

\section{Idle Gear Rattle}

\author{
S. Theodossiades ${ }^{*}$, O. Tangasawi and H. Rahnejat \\ Wolfson School of Mechanical \& Manufacturing Engineering, \\ Loughborough University, LE11 3TU, Loughborough, UK
}

PAGES: 67

FIGURES: 16

* Corresponding author. Tel: +44 1509 227664; Fax: +44 1509 227648;

e-mail: S.Theodossiades@lboro.ac.uk 


\section{ABSTRACT}

The rattle phenomenon in vehicular transmissions and its impact on the automotive industry have been widely reported in the literature. A variety of palliative measures have been suggested for attenuation of rattle such as use of backlash eliminators, clutch dampers or dual-mass flywheels. These palliative measures incur further costs and can have untoward implications in powertrain noise and vibration problems. A fundamental investigation of the dynamics of impacting gears is undoubtedly the way forward for a root cause solution. This paper introduces a new approach for understanding the interactions between the transmission gears during engine idle conditions by taking into account the effect of lubrication. Gear impacting surfaces are treated as lubricated conjunctions rather than the usually reported dry impacting solids. Depending on load and speed of entraining motion of the lubricant into the contact domains, the regime of lubrication alters. In this paper, the influence of lubricant in torsional vibration of lightly loaded idling gears is examined which promotes iso-viscous hydrodynamic conditions. It is shown that the lubricant film under these conditions behaves as a time-varying nonlinear spring-damper element. Spectral analysis of the system response is compared to the findings of the linearised system.

\section{KEYWORDS}

Transmission idle gear rattle, hydrodynamic regime of lubrication, lubricant stiffness.

\section{NOTATION}

C Clearance between gear and shaft. 


\begin{tabular}{|c|c|}
\hline$C_{b}$ & Gear teeth half normal backlash. \\
\hline$F$ & Petroff friction force. \\
\hline$F_{f}$ & Hydrodynamic flank friction force. \\
\hline$F_{i(i=1 \ldots 6, \text { rev })}$ & Hydrodynamic load on the $i^{\text {th }}$ tooth flank \\
\hline$h$ & Lubricant film thickness. \\
\hline$I_{i(i=1,2,3,4,5,6)}$ & Moment of inertia of the $i^{\text {th }}$ gear wheel. \\
\hline$I_{\text {prev }}$ & Moment of inertia of reverse pinion \\
\hline$I_{\text {wrev }}$ & Moment of inertia of reverse gear wheel \\
\hline K & Linear lubricant stiffness. \\
\hline$K_{o i(i=1, \ldots, 6)}$ & Mean lubricant stiffness of the $i^{\text {th }}$ gear pair. \\
\hline$K_{o(\text { rev })}$ & Mean lubricant stiffness of reverse gear pair. \\
\hline$K_{c p}$ & Amplitude of the alternating lubricant component (the $p^{\text {th }}$ cosine term). \\
\hline$K_{s p}$ & Amplitude of the alternating lubricant component (the $p^{\text {th }}$ sine term). \\
\hline$L$ & Length of contact line \\
\hline$l$ & The distance between the instantaneous contact point and the pitch point. \\
\hline$l_{1}$ & Length of the conformal contact surface between idle gear and shaft \\
\hline$n_{i}$ & The tooth number of the $i^{\text {th }}$ gear wheel. \\
\hline$r_{b}$ & Base radius. \\
\hline$r_{c}$ & Radial distance of pinion and wheel contact point \\
\hline eq & The equivalent curvature radius of two teeth surfaces at their contact point \\
\hline
\end{tabular}


taken at the normal plane.

$r_{\text {os }} \quad$ Radius of the output shaft

$r_{p} \quad$ Contact radius of the pinion.

$r_{p p} \quad$ Pitch radius of the pinion.

$r_{\text {prev }} \quad$ Contact radius of the reverse speed pinion

$r_{w w} \quad$ Pitch radius of the gear wheel.

$r_{\text {wi }(i=1 \ldots, \ldots, \text { rev })} \quad$ Contact radius of the $i^{\text {th }}$ gear wheel.

$T_{\text {fwi }(i=1 \ldots, \ldots, r e v)} \quad$ Flank friction torque on the $i^{\text {th }}$ gear wheel.

$T_{\text {tractwi (i=1..., rev) }}$ Tractive torque between the output shaft and the $i^{\text {th }}$ gear wheel

$u \quad$ Entraining speed of gear teeth during meshing action

$u_{s} \quad$ Sliding velocity of the meshing gear teeth surfaces

$v \quad$ Tangential velocity between idle gear and supporting shaft

$v_{w} \quad$ Rolling velocity of the gear wheel tooth surface.

$v_{p} \quad$ Rolling velocity of the pinion tooth surface.

$v_{\text {pitch }, p} \quad$ Pitch velocity of the pinion.

$v_{\text {pitch,w }} \quad$ Pitch velocity of the gear wheel.

W Lubricant hydrodynamic reaction.

$\alpha_{n} \quad$ Normal pressure angle.

$\alpha_{t} \quad$ Transverse pressure angle.

$\beta \quad$ Pitch circle helix angle. 
$\beta_{b} \quad$ Base circle helix angle.

$\Delta \quad$ Contact lines inclination angle.

$\eta_{0} \quad$ Dynamic viscosity at atmospheric conditions.

$\rho_{p} \quad$ Curvature radius of the pinion tooth surface in the transverse plane.

$\rho_{w i} \quad$ Curvature radius of the $i^{\text {th }}$ gear wheel tooth surface in the transverse plane.

$\varphi_{1, \text { prev }} \quad$ Angular displacement of the $1^{\text {st }}$ speed gear and reverse pinion

$\varphi_{i(i=2 \ldots 6)} \quad$ Angular displacement of $2^{\text {nd }}, 3^{\text {rd }}, 4^{\text {th }}, 5^{\text {th }}$ and $6^{\text {th }}$ idle gear wheels

$\varphi_{\text {in }} \quad$ Angular displacement of the input shaft

$\varphi_{i T} \quad$ Fundamental period of the impacting stiffness

$\varphi_{\text {wrev }} \quad$ Angular displacement of the reverse speed gear

$\varphi_{p}, \varphi_{w} \quad$ Pinion and gear angular displacements

$\dot{\varphi}_{\text {os }} \quad$ Output shaft rotational speed, here $\dot{\varphi}_{\text {os }}=0$

\section{Subscripts}

$\begin{array}{ll}p & \text { Pinion } \\ \text { prev } & \text { Pinion of reverse gear } \\ w & \text { Gear wheel } \\ \text { wrev } & \text { Wheel of reverse gear }\end{array}$

\section{INTRODUCTION}

The idle gear rattle phenomenon is associated with the characteristic noise that unselected impacting gears radiate to the environment. The phenomenon occurs at low 
impact forces, qualitatively similar to the noise produced, when a marble hits a tin can. The problem is induced by engine order vibrations in the presence of backlash in meshing pairs, and is particularly troublesome in vehicles with diesel engines, because of higher output torques (Sakai et al [1]). Rattle has a distinct sound quality that differentiates it from noises produced by other sources in the vehicle (Dogan and Lechner [2]), while the attenuation of engine noise during the past decades has brought it to the forefront of noise and vibration issues, as a major concern for the automotive industry (Wang et al [3]). Vehicle owners are usually annoyed by this noise and often attribute it to some form of malfunction. In addition to possible warranty claims, a low quality image accompanies the manufacturers' products.

Idle gear rattle is primarily caused by the torsional vibration of the gearbox input shaft due to the transmitted combustion and inertia fluctuations of the engine crankshaft, when the latter operates in idle conditions (Seaman et al [4], Fujimoto et al. [5], Fujimoto and Kizuka [6]). As a result, the transmission gears oscillate and impact with each other. Most of the system energy manifests itself in torsional vibrations at harmonics of the engine speed, superimposed upon the gears' angular motions. A part of these oscillations is transmitted through to the bearing mounts and transmission shafts to the gearbox housing and is radiated to the environment as noise (Sakai et al [1], Wang et al [3]).

The rattle phenomenon is largely associated with the unselected (idler) gears, which are free to rotate on their bearings. This can be explained by the occurring tooth separation, when the driving gear has higher deceleration than the idler gear (Johnson and Hirami [7] Fujimoto et al. [5]). If the drag torque on the idler gear is increased, it decelerates more, thus minimising the amount of separation. This agrees with what has been reported in 
literature (e.g. Seaman et al [4]) that rattle severity decreases, when the drag torque in idle gears is increased. Since the selected gears are loaded externally, they decelerate under the influence of the external load, which is acting as a "drag", and when it is sufficient prevents separation and, thus, rattle. Rivin [8] has also reported that lightly loaded gears are more prone to separation and impacts. Experiments have shown that there are certain thresholds, at which rattle makes its appearance (Sakai et al [1]). These observations are based on the relationship between the inertial torque of the loose rotating gears and the drag torque on the teeth flanks. Seaman et al [4] have defined the rattle threshold as the angular acceleration, at which the inertial torque at the unloaded gear exceeds the drag torque. Other experimental investigations have focused on the drag torque and the influence of bulk oil temperature on the propensity to rattle. It has been reported that drag torque is higher at lower temperatures (Sakai et al [1], Seaman et al [4], Fujimoto et al [5], and Gohar [9]). Moreover, it has been shown that rattle noise attenuates at lower temperatures (Sakai et al [1], and Seaman et al [4]). Since lubricant viscosity decreases with rising temperature, thus the resistance to motion in lubricated conjunctions is reduced (Gohar [9]). Thus, rattle is also a temperature-dependent phenomenon. Changing the dynamic viscosity of the lubricant by an order of magnitude, Gnanakumarr et al [10] showed, through a numerical simulation study, that the effect of most engine orders can be eliminated. This leads rattle response in the extreme high-viscosity case to the natural frequency of the lubricant film, which is acting as a non-linear spring. However, in practice, there exists a limit for the viscosity of the transmission fluid, before excessive drag torque results in inefficient transmission. The study by Gnanakumarr et al 
[10] was isothermal and high lubricant viscosity can lead to shear heating. It is clear that a viscous transmission fluid is desired in the contact of loose gears to their bearings, but not desired in teeth flank contacts. Nevertheless, recent experimental results published by Fujimoto and Kizuka [6] have shown that there is a temperature range, at which rattle remains at minimum levels.

Seaman et al [4] have pointed to reduction of idle rattle by increasing the engine idling speed at the expense of fuel consumption. Additionally, the rotational fluctuations at the flywheel can be attenuated by increasing the flywheel mass or utilising a Dual Mass Flywheel (DMF) system (Fudala et al [11]). The former method would incur a fuel consumption penalty and increased stressing of the crankshaft (Seaman et al [4]), while the latter is costly and deteriorates the engine torsional vibrations due to a decrease in the inertia of DMF's primary mass member. Therefore, a conundrum is arrived at, whereupon an improvement in idle rattle can lead to increased engine order response. Tuning the clutch pre-damper and hysteresis characteristics may also improve rattle performance, but can worsen another important transient NVH phenomenon, referred to as clonk (Seaman et al [4], Theodossiades et al [12]).

Increasing drag torque is a low-cost option (Kim and Singh [13]), which can reduce rattle (Seaman et al [4], Bellomo et al [14]). However, this would render an additional shift effort, while also increasing the frictional losses and the transmission operating temperature, as already noted (Seaman et al [4], Kim and Singh [13]). Using gears with very low backlash would not be a practical solution due to unavoidable manufacturing errors and impracticalities in gear operation, even though it has been theoretically found that it eliminates rattle (Biermann and Hagerodt [15]). Moreover, Seaman et al [4] have 
reported that zero-backlash causes gear growl. The use of backlash eliminators has also the drawbacks of increasing friction losses and generating unacceptable heat (Rivin [8]). Furthermore, it possibly leads to whistling noise, as also reported by Fujimoto and Kizuka [16].

A common approach in numerical investigations of gear rattle is to model the driveline as a lumped parameter system with hysteresis. The gear backlash is usually included using the dead space function (Kim and Singh [13]). The clutch stiffness and hysteresis have been modelled as piece-wise linear functions (Singh et al [17], Kim and Singh [13], Fujimoto and Kizuka [16], [18]). Drag torque is usually added, being proportional to the rotational speed, with the drag torque coefficient either assumed as constant (Kim and Singh [13]) or temperature dependent (Fujimoto and Kizuka [16], [18]]). The gear teeth stiffness has been assumed as constant in many investigations (Sakai et al [1], Kim and Singh [13], Meisner and Campbell [19]). Time-varying contact stiffness coefficients were utilised by Kahraman and Singh [20], Blankenship and Singh [21], Wang et al [22], Yakoub et al [23] and Theodossiades and Natsiavas ([24] and [25]), which also take into account the contact ratio variation and the gear teeth elastic properties.

Generally, dry gear teeth impacts have been considered in rattle investigations. The effect of lubricant film has not been included in full transmission models, in order to keep the complexity level low. Nevertheless, Gnanakumarr et al [10] proposed a lubricated contact model that assumes a hydrodynamic film present in gear teeth contacts for lightly loaded idle rattle conditions. Thus a hydrodynamic force rather than an elastic force is applied between the gear surfaces, depending on the lubricant entrainment speed, the contact geometry, and the approach velocity between the teeth - referred to as squeeze film 
velocity (Rahnejat [26]). The drag force in the study by Gnanakumarr et al [10] was the Petrov friction, which depends on the lubricant entraining velocity in the clearance zone between the loose gear and its shaft and the geometry of these two contacting bodies. However, this model is also simplified, as it assumes that gear tooth contact takes place at the pitch circle at all times. It should be noted that in most of the literature, drag torque was modelled as linear damping force with constant coefficient (e.g. Sakai et al [1], Kim and Singh [13], and Singh et al [17]), or with temperature dependent coefficients (Fujimoto and Kizuka [6]). In lubricated contacts the effective contact stiffness is the equivalent stiffness of the lubricant film and the elastic teeth members (Rahnejat [26]). In highly loaded contacts, the lubricant becomes incompressible and its stiffness far exceeds that of the adjacent elastic solids, thus may be ignored. The regime of lubrication that leads to this condition is now well-understood and is referred to as elastohydrodynamics (Gohar [9], Rahnejat [26]). However, under lightly loaded conditions the converse of the problem is true. In this sense, Gnanakumarr et al [10] hydrodynamic contact model is suitable for idle rattle conditions.

This paper reports a numerical investigation of a front wheel drive six-speed manual transmission system under idle rattle conditions. The dynamic model includes tooth geometrical characteristics, kinematics of contact, hydrodynamic lubricant film formation and effect of lubricant rheology. The results of the numerical analysis are compared to findings of the linearised system and a parametric study of the lubricant effect is presented. It is shown that the lubricant is a dominant factor, determining the system behaviour. 


\section{THE TRANSMISSION MODEL}

The layout of a front wheel drive transaxle gearbox is shown in figure 1. It comprises an input shaft at engine torque and two output shafts, transmitting torque to the front wheels via the differential unit. When either of the two output shafts is engaged via a synchroniser, the other output shaft rotates on its bearings at constant mesh with the differential ring gear. Since there are no gears engaged on the output shafts under engine idle conditions, neither of the output shafts transmits any torque.

The angular displacement, $\varphi_{\text {in }}(t)$, velocity $\dot{\varphi}_{\text {in }}(t)$ and acceleration $\ddot{\varphi}_{\text {in }}(t)$ histories of the input shaft are known, using real data from experimental measurements in a vehicle equipped with the same transmission type. As a consequence, the motion of the system is adequately described by the following set of generalized coordinates, $\left(\begin{array}{lllllll}\varphi_{1, \text { prev }} & \varphi_{2} & \varphi_{3} & \varphi_{4} & \varphi_{5} & \varphi_{6} & \varphi_{\text {wrev }}\end{array}\right)^{T}$, where $\varphi_{1, \text { prev }}$ corresponds to the gear of the $1^{\text {st }}$ speed and the pinion of the reverse, $\varphi_{\text {wrev }}$ is the rotation of the reverse speed gear and $\varphi_{i(i=2 \ldots 6)}$ corresponds to the gears of the other pairs.

The corresponding equations of motion are formulated as follows:

For the $1^{\text {st }}$ idle gear wheel (which is combined with the reverse speed pinion, as shown in figure 1):

$$
\begin{aligned}
\left(I_{1}+I_{\text {prev }}\right) \ddot{\varphi}_{1, \text { prev }}= & F_{1}\left(\varphi_{1, \text { prev }}, \varphi_{\text {in }}, \dot{\varphi}_{1, \text { prev }}, \dot{\varphi}_{\text {in }}\right) r_{w 1} \\
& -F_{\text {rev }}\left(\varphi_{\text {wrev }}, \varphi_{1, \text { prev }}, \dot{\varphi}_{\text {wrev }}, \dot{\varphi}_{1, \text { prev }}\right) r_{\text {prev }} \\
& -T_{\text {fw } 1}\left(\varphi_{1, \text { prev }}, \varphi_{\text {in }}, \dot{\varphi}_{1, \text { prev }}, \dot{\varphi}_{\text {in }}\right)-T_{\text {tractw } 1}\left(\dot{\varphi}_{1, \text { prev }}\right)
\end{aligned}
$$

For the $2^{\text {nd }}$ idle gear wheel:

$$
I_{2} \ddot{\varphi}_{2}=F_{2}\left(\varphi_{2}, \varphi_{\text {in }}, \dot{\varphi}_{2}, \dot{\varphi}_{\text {in }}\right) r_{\text {w2 }}-T_{\text {fw2 }}\left(\varphi_{2}, \varphi_{\text {in }}, \dot{\varphi}_{2}, \dot{\varphi}_{\text {in }}\right)-T_{\text {tractw } 2}\left(\dot{\varphi}_{2}\right)
$$

For the $3^{\text {rd }}$ idle gear wheel: 
$I_{3} \ddot{\varphi}_{3}=F_{3}\left(\varphi_{3}, \varphi_{\text {in }}, \dot{\varphi}_{3}, \dot{\varphi}_{\text {in }}\right) r_{\text {w3 }}-T_{\text {fw3 }}\left(\varphi_{3}, \varphi_{\text {in }}, \dot{\varphi}_{3}, \dot{\varphi}_{\text {in }}\right)-T_{\text {tractw3 }}\left(\dot{\varphi}_{3}\right)$

For the $4^{\text {th }}$ idle gear wheel:

$I_{4} \ddot{\varphi}_{4}=F_{4}\left(\varphi_{4}, \varphi_{\text {in }}, \dot{\varphi}_{4}, \dot{\varphi}_{\text {in }}\right) r_{w 4}-T_{f w 4}\left(\varphi_{4}, \varphi_{\text {in }}, \dot{\varphi}_{4}, \dot{\varphi}_{\text {in }}\right)-T_{\text {tractw } 4}\left(\dot{\varphi}_{4}\right)$

For the $5^{\text {th }}$ idle gear wheel:

$I_{5} \ddot{\varphi}_{5}=F_{5}\left(\varphi_{5}, \varphi_{\text {in }}, \dot{\varphi}_{5}, \dot{\varphi}_{\text {in }}\right) r_{\text {w5 }}-T_{f w 5}\left(\varphi_{5}, \varphi_{\text {in }}, \dot{\varphi}_{5}, \dot{\varphi}_{\text {in }}\right)-T_{\text {tractw5 }}\left(\dot{\varphi}_{5}\right)$

For the $6^{\text {th }}$ idle gear wheel:

$I_{6} \ddot{\varphi}_{6}=F_{6}\left(\varphi_{6}, \varphi_{i n}, \dot{\varphi}_{6}, \dot{\varphi}_{\text {in }}\right) r_{\mathrm{w} 6}-T_{\text {fw } 6}\left(\varphi_{6}, \varphi_{\text {in }}, \dot{\varphi}_{6}, \dot{\varphi}_{\text {in }}\right)-T_{\text {tractw6 }}\left(\dot{\varphi}_{6}\right)$

And for the reverse gear idle wheel:

$$
\begin{aligned}
I_{\text {wrev }} \ddot{\varphi}_{\text {wrev }}= & F_{\text {rev }}\left(\varphi_{\text {wrev }}, \varphi_{1, \text { prev }}, \dot{\varphi}_{\text {wrev }}, \dot{\varphi}_{1, \text { prev }}\right) r_{\text {wrev }} \\
& -T_{\text {fwrev }}\left(\varphi_{\text {wrev }}, \varphi_{1, \text { prev }}, \dot{\varphi}_{\text {wrev }}, \dot{\varphi}_{1, \text { prev }}\right)-T_{\text {tractwrev }}\left(\dot{\varphi}_{\text {wrev }}\right)
\end{aligned}
$$

In the above equations, $F_{i(i=1 \ldots, \ldots, \text { rev })}$ represent the hydrodynamic forces between the gear teeth meshing surfaces, $r_{\text {wi }(i=1 . .6, \text { rev })}$ are the contact radii of the idle gears and $r_{\text {prev }}$ is the

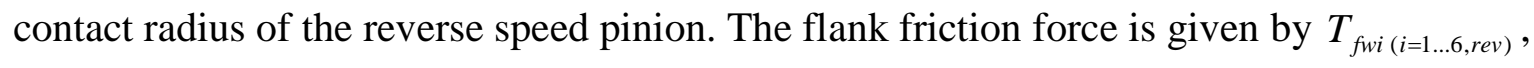
while the tractive force between the output shafts and the idle gear wheels is given by $T_{\text {tractwi }(i=1 . .6, \text { rev })}$.

\section{GEAR CONTACT CONDITIONS - MAIN FORCING ELEMENTS}

During the meshing cycle, the helical gears of the transmission system under investigation change from two to three or from three to four teeth pairs' contacts and vice versa. Therefore, an algorithm is implemented to calculate the variation of their geometric 
characteristics during the meshing cycle phases (Tangasawi et al [27]). Particular variables of interest are the teeth flank curvatures, radii and contact velocities, which are later used in the calculation of the reaction forces between the teeth flanks.

The average velocity between the pinion and gear surfaces during contact (surface velocity) influences the flow of lubricant between the gear teeth, and is referred to as the lubricant speed of entraining motion. The surface velocity can be obtained by considering the kinematics of contacting pairs at any instant of time. The lubricant entraining motion is the result of the rolling motion of the teeth pairs and is taking place orthogonal to the line of contact. Therefore, the rolling velocity of the mating teeth pairs can be determined with respect to the pitch velocities by appropriate transformation. The instantaneous pitch velocities of the pinion and gear are given, respectively, by:

$$
\left.\begin{array}{l}
v_{\text {pitch }, p}=r_{p} \dot{\varphi}_{p} \\
v_{\text {pitch }, w}=r_{w} \dot{\varphi}_{w}
\end{array}\right\}
$$

Where $\varphi_{p}, \varphi_{w}$ and $r_{p}, r_{w}$ are the angular displacements and contact radii of the pinion and gear, respectively. The components of the rolling velocities on the transverse plane are given by (Merritt [28]):

$$
\left.\begin{array}{l}
v_{p}=v_{\text {pitch }, p}\left(\sin \alpha_{t}+\frac{l}{r_{p p}}\right) \\
v_{w}=v_{\text {pitch }, w}\left(\sin \alpha_{t}-\frac{l}{r_{w w}}\right)
\end{array}\right\}
$$

In the above equations $\alpha_{t}$ is the transverse pressure angle, $r_{p p}$ and $r_{w w}$ are the pitch radii of pinion and wheel respectively, and $l$ is the distance between the instantaneous contact 
point and the pitch point, measured along the contact path (figure 2), which can be calculated as:

$l=r_{w} \sin \alpha_{t}-\rho_{w}$

where, $\rho_{w}$ is the radius of curvature of the wheel tooth. The average surface velocity (speed of lubricant entrainment) normal to the contact line, is given by (Merritt [28] and Kahraman et al [29]):

$u=\left(\frac{v_{p}+v_{w}}{2}\right)\left(\frac{\cos \beta}{\cos \beta_{b}}\right)$

Where $\beta$ and $\beta_{b}$ are the helix angles at the pitch and base circles. Since the gears are helical, the contact lines are inclined at an angle $\Delta=\cos ^{-1}\left(\frac{\cos \beta}{\cos \beta_{b}}\right)$, as shown in figure 3a (Merritt [28] and Kahraman et al [29]).

The lubricant film thickness is obtained in the normal section as follows:

$$
h= \begin{cases}C_{b}-\frac{r_{p} \varphi_{p}-r_{w} \varphi_{w}}{\cos \alpha_{n} \cos \beta}, & r_{p} \varphi_{p}>r_{w} \varphi_{w} \\ C_{b}, & r_{p} \varphi_{p}=r_{w} \varphi_{w} \\ C_{b}+\frac{r_{p} \varphi_{p}-r_{w} \varphi_{w}}{\cos \alpha_{n} \cos \beta}, & r_{p} \varphi_{p}<r_{w} \varphi_{w}\end{cases}
$$

where $2 C_{b}$ is the total normal backlash between the gear teeth and $\alpha_{n}$ is the normal pressure angle.

The squeeze velocity with first order approximation is given as: 


$$
\frac{\partial h}{\partial t}= \begin{cases}-\frac{r_{p} \dot{\varphi}_{p}-r_{w} \dot{\varphi}_{w}}{\cos \alpha_{n} \cos \beta}, & r_{p} \varphi_{p}>r_{w} \varphi_{w} \\ 0, & r_{p} \varphi_{p}=r_{w} \varphi_{w} \\ \frac{r_{p} \dot{\varphi}_{p}-r_{w} \dot{\varphi}_{w}}{\cos \alpha_{n} \cos \beta}, & r_{p} \varphi_{p}<r_{w} \varphi_{w}\end{cases}
$$

Although gear rattle has been treated by a number of recent investigations, most models disregard the action of the intervening lubricant in the impact zone. In low or nonconformal conjunctions, such as the contact of meshing teeth, four regimes of lubrication are possible: piezo-viscous rigid, piezo-viscous elastic (referred to as elastohydrodynamics), iso-viscous elastic and iso-viscous rigid. Rigid or elastic refers to the behaviour of the teeth surfaces under the instantaneous contact load, whilst iso-viscous and piezo-viscous refer to the lubricant rheological state under the same load. In this paper iso-viscous rigid hydrodynamic conditions has been assumed due to the low loads $(<20 \mathrm{~N})$ experienced by the gear teeth under engine idle conditions. With such lightly loaded contacts the regime of lubrication is iso-viscous rigid (hydrodynamics) (see Appendix A). The lubricant reaction $W$ for such conjunctions was derived by Rahnejat [26], in a similar way to that derived independently by Sasaki et al [30] and is given by:

$$
W= \begin{cases}\frac{L \eta_{0} r_{e q}}{h}\left(2 u-\frac{3 \pi}{\sqrt{\frac{2 h}{r_{e q}}}} \frac{\partial h}{\partial t}\right), & \frac{\partial h}{\partial t}<0 \\ \frac{L \eta_{0} r_{e q}}{h}(2 u), & \frac{\partial h}{\partial t} \geq 0\end{cases}
$$


where $L$ is the length of the contact line and $\eta_{0}$ is the atmospheric dynamic viscosity of the lubricant. Note that a negative value for $\frac{\partial h}{\partial t}$ indicates mutual approach (squeezing) of the meshing gear teeth, whilst a positive value indicates separation, which does not contribute to the load carrying capacity of the contact zone. A value of zero indicates pure rolling condition. The equivalent radius of curvature normal to the line of contact $r_{e q}$ is approximately taken at the position along the line of contact that lies on the diagonal of the contact plane as (Merritt [28]):

$r_{e q}=\frac{\rho_{p} \rho_{w}}{\left(\rho_{p}+\rho_{w}\right) \cos \beta_{b}}$

where $\rho_{p}$ and $\rho_{w}$ are the pinion and wheel tooth surface radii of curvature in the transverse plane.

It is noteworthy that the other principal radii of contact (across the profile of the teeth flanks) are considered as infinite compared to $\rho_{p}$ and $\rho_{w}$, since there are orders of magnitude difference between them. This assumption leads to contact footprints, which are slanted lines at any time. In reality the length of the contact line is finite and clearly alters, as shown in figure 3b. This means that equation (14), based on the assumption of an infinite line contact is a reasonable approximation under lightly loaded hydrodynamic conditions, since with no deformation of the impacting solids the width of contact is almost negligible. The torque due to the hydrodynamic load $W$ (illustrated in figures 4 and 5), causing the rotating action is given by:

$F_{i(i=1 \ldots, \ldots, r e v)} r_{w i}=W_{i} \cos \alpha_{n} \cos \beta r_{w i}$. 
Where $r_{w i}$ is the contact radius given by:

$r_{w i}=\sqrt{\rho_{w i}^{2}+r_{b}^{2}}$

where $r_{b}$ is the base radius and $\rho_{w i}$ denotes the curvature radius of the wheel tooth.

The motions of the idle gear wheels are resisted by hydrodynamic traction induced by a film of lubricant formed between the output shaft's convex curvature and the inside concave surface of the gears, as shown in figure 5. This force is known as the Petrov friction (Hamrock et al [32]), which is valid for low load conditions (Taylor [33]); for a concentric arrangement with zero eccentricity it can be written in the following form (Gnanakumarr et al [10]):

$F=\frac{\pi \eta_{0} v l_{1} r_{o s}}{C}$

where $r_{o s}$ is the radius of the output shaft, $C$ is the clearance between the shaft and the idle gear, $l_{1}$ is the length of contact line, and $v$ is the entraining velocity of the lubricant in this conforming conjunction, calculated as follows (Gnanakumarr et al [10]):

$v=\frac{1}{2}\left[\left(r_{o s}+C\right) \dot{\varphi}_{w}+\frac{1}{2 \pi} r_{o s} \dot{\varphi}_{o s}\right]$

where $\dot{\varphi}_{\text {os }}$ is the output shaft rotational speed (in neutral, $\dot{\varphi}_{\text {os }}=0$ ). The resistive torque generated is given by:

$T_{\text {tract }}=F r_{o s}$

The hydrodynamic flank friction acts in or opposite to the e-direction (figure 3a), parallel to the flank end faces (figures $3 \mathrm{~b}$ and 4) and is defined as follows (derived from Gohar [9] using half-Sommerfeld conditions, see Appendix B): 


$$
F_{f}=\left\{\begin{array}{cl}
\frac{L \pi \eta_{0} u_{s}}{\sqrt{2 h}} \sqrt{r_{e q}}, & u_{s} \geq 0 \\
\frac{L \pi \eta_{0}\left(-u_{s}\right)}{\sqrt{2 h}} \sqrt{r_{e q}}, & u_{s}<0
\end{array}\right.
$$

where $u_{s}$ is the gear teeth surface sliding velocity given by

$$
u_{s}=v_{p}-v_{w}
$$

Negative sign is used in equation (21), since the rotational angles of the pinion and wheel are both positive. Clearly, the sense of application of friction force alters in line with the direction of fluid entrainment, although this is not immediately clear in equation (21). Thus, the torque given by equation (23) always opposes the motion. Therefore, the torque due to teeth flank friction is defined as:

$T_{f}=r_{w} F_{f} \sin \alpha_{t}$

\section{RESULTS AND DISCUSSION}

The computational flow-chart is shown in figure 6. Based on the initial conditions, the geometric quantities and meshing cycle characteristics of the idle gears are determined. In turn, these are used for the computation of the reaction forces on the flanks and between the gears and the output shafts. The case examined corresponds to typical values for the gear backlash between the various gear pairs (from 80 to $150 \mu \mathrm{m}$ ), lubricant dynamic viscosity (0.052 $\mathrm{Pa} \cdot \mathrm{s}$, corresponding to $44^{\circ} \mathrm{C}$ temperature) and engine speed in idle (810 rpm). The equations of motion are solved numerically, using the linear acceleration method (Timoshenko et al [34]) for 30s of real time, which corresponds approximately to 
1.5 hours in a Pentium IV 2.8 GHz desktop machine. This period of time is sufficient to eliminate transient phenomena from the responses, which appear at the beginning of the simulation due to the initial conditions. It is noteworthy that idle rattle is a steady state NVH phenomenon (Comparin and Singh [35]), which does not depend on initial conditions or engine start-up.

The most important excitation source is engine order vibration, which leads to torsional oscillations of the transmission input shaft, superimposed upon its nominal angular velocity (Rahnejat [36]). For a 4-cylinder, 4-stroke in-line engine considered here, the main inertial dynamic contributions occur at even engine orders. Figure 7 shows the vibration spectrum of the transmission input shaft torsional oscillation response, which has been acquired from the vehicle under investigation and used as an input to the numerical model. Note the various engine orders up to and including the 9th order $(121.2 \mathrm{~Hz})$. These contributions are evident (see later) in the spectra of vibration of all the idle gears. As expected the most significant is the $2^{\text {nd }}$ engine order $(26.6 \mathrm{~Hz})$ with other main contributions at $4^{\text {th }}(53.1 \mathrm{~Hz}), 6^{\text {th }}(79.5 \mathrm{~Hz})$ and $8^{\text {th }}(107 \mathrm{~Hz})$ engine orders.

Figure 8 shows the time histories of the idle gears' angular acceleration for all gear sets. With the vibration severity clearly varying between the different gear pairs, it can be concluded that the overall response of an idle gear consists of two particular motions: the "macroscopic" motion, and the "microscopic" fluctuations, containing different frequency characteristics. The lower frequency engine orders are expected to be dominant in the macroscopic regions, while the higher vibro-impact frequencies are expected to govern the "microscopic" fluctuations. Similar behaviour is also encountered in the graphs of figure 9, where the lubricant film thickness time histories of the idle gear pairs are presented. The 
gears with lower inertia ( $5^{\text {th }}$ and $6^{\text {th }}$ gear wheels) develop lubricant films of lower thickness compared to the idle pairs of high inertia $\left(1^{\text {st }}, 2^{\text {nd }}\right.$ and reverse gear wheels). Nevertheless, in all cases the size of the film thickness is within a range compatible with the initially assumed hydrodynamic conditions, varying between 1.5 - 10 $\mu \mathrm{m}$, depending on the gear pair. Moreover, the lower inertia gear pairs demonstrate higher fluctuations of the lubricant film thickness, which can be interpreted as higher frequency content in the corresponding vibration spectra. An important point to note is that the squeeze film velocity is of the order of $1-2 \mathrm{~mm} / \mathrm{s}$ in approaching surfaces. Although this value may appear to be significant, it is in fact three orders of magnitude lower than the speed of entraining motion. Thus, the contribution to reaction load due to squeeze is very small compared with that due to entraining motion. It is even less significant in increased pressure gradient, contributing to flank friction. This point is further discussed in Appendix B.

Figure 10 shows the FFT spectra of the lubricant film thickness for all gear sets. The way the film thickness changes reveals the frequencies under which the gear flanks approach and separate from each other. It is noteworthy that in most gear wheels, the highest amplitude contributions coincide with the various engine order harmonics, which are contained in the motion of the transmission input shaft (as described above). The idle gear pairs with lower inertias generally exhibit higher amplitudes of oscillations and broader spectral content compared to the high inertia pairs. However, this is not an indication that rattle should be mostly expected from the lower inertia gear sets, since it is the relationship between drag resistance and inertia torque values, which governs the appearance of rattle (Seaman et al [4]). Other sources contributing to the spectral content 
are the gear meshing frequencies and the torsional natural frequencies of the transmission system.

Figure 10a shows the FFT spectrum of the $1^{\text {st }}$ gear pair film thickness. The engine orders clearly dominate the response. Similar observations can also be made in the spectra of figs. $10 \mathrm{~b}-10 \mathrm{~g}$, for other idle gears. In those spectra, the engine orders are again dominant, but other frequencies are also present. Specifically, $372 \mathrm{~Hz}$ in the $3^{\text {rd }}$ gear (figure 10c) is very close to the gear pair meshing frequency $(384 \mathrm{~Hz})$, while the reverse gear spectrum (figure 10g) includes contribution from the reverse meshing frequency (107 Hz). Still a number of higher frequency contributions appear in those spectra, which do not correspond either to engine orders, or to gear meshing frequencies and their multiples.

By examining the Auto Regressive (AR) spectra of the idle gear wheels' microscopic fluctuations, as shown in figure 11, it can be seen that the aforementioned higher frequency contributions are dominant. In contrast to the FFT method, which is an averaging process, the Auto Regressive method offers accurate frequency estimation for data records of short time [37]. The "spikes" appearing in the $\ddot{\varphi}$ and $h$ time histories (figs. 8 and 9) are of very short nature, containing the vibro-impact frequencies of the mechanism. The main frequencies identified by examining those peaks are the following: $221 \mathrm{~Hz}$ for the $1^{\text {st }}, 208 \mathrm{~Hz}$ for the $2^{\text {nd }}, 344 \mathrm{~Hz}$ for the $3^{\text {rd }}, 218 \mathrm{~Hz}$ for the $4^{\text {th }}, 1015 \mathrm{~Hz}$ for the $5^{\text {th }}, 407 \mathrm{~Hz}$ for the $6^{\text {th }}$ and $151 \mathrm{~Hz}$ for the reverse gear. These frequencies are "carrying" most of the energy content that is included in the microscopic fluctuations of the gear wheels and can also be observed in the FFT spectra of the film thickness (although significantly reduced or modulated in cases, such as the $1^{\text {st }}, 3^{\text {rd }}, 4^{\text {th }}, 6^{\text {th }}$ and 
reverse gears). Naturally, their presence is not dominant in the FFT spectra, because of the short duration of the microscopic "spikes" compared to the overall macroscopic response.

For better understanding of these contributions, the effect of the lubricant on the system dynamics must be ascertained. Since the lubricant film is the main factor determining the interactions between the gear flanks - behaving as a nonlinear spring, which follows the meshing cycle variation - it is additionally important to calculate the natural frequencies of the mechanical model and observe any interactions indicated by the normal modes of the torsional linear system. The natural frequencies of the model arising through linearization of equations (1) - (7) are calculated. This process also includes the equation of motion of the input shaft. The lubricant stiffness is determined by differentiating Eq. (14) with respect to the film thickness, considering the rolling term only. This assumption is reasonable, because firstly the differentiation of the squeeze film term is only valid in normal approach (i.e. $\partial h / \partial t<0$ ) and secondly that its contribution is negligible as $\partial h / \partial t<<<u$ in eq. (14). Thus the torsional gear stiffness is given by:

$$
K\left(\varphi_{i}\right)=\left|\frac{\partial W_{i}}{\partial h_{i}}\right|
$$

The lubricant stiffness between the various pairs of meshing gear teeth is a function of time, since it depends on the film thickness and contact kinematics as a function of the rolling/sliding geometry. In a similar approach, the damping action of the lubricant is contained in the squeeze film term of Eq. (14), which depends on $\partial h / \partial t$ and it is also a function of time. If the tooth-to-tooth variations are neglected, the fundamental period of the impacting stiffness is equal to $\varphi_{i T} \equiv 2 \pi / n_{i}$, where $n_{i}$ represents the tooth number of 
the driving gear (Theodossiades and Natsiavas [25]). Therefore, the lubricant stiffness can be approximately expressed in a Fourier series as follows:

$$
K\left(\varphi_{i}\right)=K_{0 i}+\sum_{p=1}^{\infty} K_{c p} \cos \left(p n_{i} \varphi_{i}\right)+K_{s p} \sin \left(p n_{i} \varphi_{i}\right)
$$

The equations of motion for the linearised model are formulated as follows, neglecting the damping terms:

For the input shaft

$$
I_{i n} \ddot{\varphi}_{i n}+\sum_{i=1}^{6} K_{0 i} r_{p i}\left(r_{p i} \varphi_{i n}-r_{w i} \varphi_{i}\right)=0
$$

For the $1^{\text {st }}$ speed idle gear (combined with the reverse gear pinion)

$$
\left(I_{1}+I_{\text {prev }}\right) \ddot{\varphi}_{1, \text { prev }}+K_{01} r_{\text {w1 }}\left(r_{w 1} \varphi_{1, \text { prev }}-r_{p 1} \varphi_{\text {in }}\right)+K_{0(\text { rev })} r_{\text {prev }}\left(r_{\text {prev }} \varphi_{1, \text { prev }}-r_{\text {wrev }} \varphi_{\text {wrev }}\right)=0
$$

For the $2^{\text {nd }}$ speed idle gear

$$
I_{2} \ddot{\varphi}_{2}+K_{02} r_{w 2}\left(r_{w 2} \varphi_{2}-r_{p 2} \varphi_{i n}\right)=0
$$

For the $3^{\text {rd }}$ speed idle gear

$$
I_{3} \ddot{\varphi}_{3}+K_{03} r_{w 3}\left(r_{w 3} \varphi_{3}-r_{p 3} \varphi_{i n}\right)=0
$$

For the $4^{\text {th }}$ speed idle gear

$$
I_{4} \ddot{\varphi}_{4}+K_{04} r_{w 4}\left(r_{w 4} \varphi_{4}-r_{p 4} \varphi_{i n}\right)=0
$$

For the $5^{\text {th }}$ speed idle gear

$$
I_{5} \ddot{\varphi}_{5}+K_{05} r_{w 5}\left(r_{w 5} \varphi_{5}-r_{p 5} \varphi_{i n}\right)=0
$$

For the $6^{\text {th }}$ speed idle gear 
$I_{6} \ddot{\varphi}_{6}+K_{06} r_{w 6}\left(r_{w 6} \varphi_{6}-r_{p 6} \varphi_{i n}\right)=0$

For the reverse speed idle gear

$$
I_{\text {wrev }} \ddot{\varphi}_{\text {wrev }}+K_{\text {orev }} r_{\text {wrev }}\left(r_{\text {wrev }} \varphi_{\text {wrev }}-r_{\text {prev }} \varphi_{1, \text { prev }}\right)=0
$$

The solution of the eigenvalue problem determines the natural frequencies and normal modes of the system, which are shown graphically in figure 12 for the case examined. Generally, the lower the hydrodynamic film thickness, the higher the natural frequency of the corresponding gear pair (Tangasawi et al [27]). In fact the stiffness of the film is proportional to $1 / h^{2}$. Furthermore, the natural frequency of every pair appears in its response spectrum, but it is not the major dominant factor. Nevertheless, in the $3^{\text {rd }}, 4^{\text {th }}, 5^{\text {th }}$, $6^{\text {th }}$ and reverse gear responses (figs. $10 \mathrm{c}-10 \mathrm{~g}$, respectively) the natural frequencies play important roles, as indicated by their contributions in the spectra. The normal modes also reveal that the motions of the $1^{\text {st }}, 4^{\text {th }}$ and reverse gears are strongly coupled, whilst a weaker form of coupling exists between the $3^{\text {rd }}$ and $6^{\text {th }}$ gears. However, the torsional natural frequencies are dominant in the AR spectra, as it can be seen by comparing the frequency values in the graphs of figure 11 with those of figure 12. In all cases, the observed deviations are lower than $10 \%$.

The importance of the lubricant stiffness is demonstrated in the graphs of figure 13 . Here, the AR spectra of the lubricant film thickness for the defined microscopic fluctuations are presented for all gear pairs, corresponding to lubricant temperature of $20^{\circ} \mathrm{C}$ (higher lubricant viscosity than the previous case). The lubricant viscosity in fact was altered by an order of magnitude (0.3 Pa.s). This is quite reasonable given the range of contact conditions, engine operation and widespread geographical use of such vehicles. It 
can be seen that there is a broader frequency content with higher contributions, altering the quality of the radiated vibration and noise from the transmission. Moreover, the parametric study of lubricant viscosity and its effect on the mechanical system response reveals an interesting scenario, which is shown in figure 14. The Root Mean Square (RMS) values of the idle gears' rotational acceleration clearly show a downward trend towards a minimum value in a certain temperature range. This phenomenon is in agreement with the findings of Fujimoto and Kizuka [6], who showed that rattle noise levels are particularly low within a specific temperature range, which is reached in the gearbox after a given period of engine operation. The reduction of lubricant viscosity, as temperature increases, has a positive effect on the gear rattle noise radiated to the environment. In the aforementioned temperature range, the lubricant stiffness becomes critically small to permit smooth transmission of motion between the gear teeth pairs during the meshing cycle. The multiple impacts between teeth are significantly reduced and thus, vibration amplitudes are generally lowered. The graphs of figure 14 show that vibration levels are particularly low in the range $40-50^{\circ} \mathrm{C}$ for the particular examined transmission system. A slightly shifted temperature range has been identified by Fujimoto and Kizuka [6] experimentally, in a vehicle equipped with a 4-cylinder diesel engine and a 5-speed manual transmission. The investigations here show the existence of an inter-play between the effects of hydrodynamic reaction in meshing pairs and the drag torque between the loose gear and output shaft. Since the same lubricant is used in both cases and the geometry of contact differs, changes in lubricant viscosity can make one dominate in certain circumstances and the other in other occasions, depending on contact kinematics and number of meshing pairs. The situation is, therefore, complex, but the significant role of this interaction is 
clear. Variations between mechanical systems - affecting the overall system behaviour are generally expected, since the geometric characteristics of the gears change significantly between different types of vehicles.

\section{CONCLUSIONS}

A new methodology for the identification and study of idle gear rattle in automotive manual transmissions has been proposed, taking into account the effect of lubricated contacts in the mechanical system. Strong interactions have been recorded between the idle gears, governed by the gear meshing frequencies and the natural frequencies of the system, determined by the hydrodynamic films. In the overall response, the engine orders are dominant, while in the microscopic fluctuations the natural frequencies of the system have the strongest presence. The lubricant behaves like a non-linear spring damper, which significantly affects the response of idle gears during the meshing cycle. The examination of the linearised system has revealed that the system response is strongly affected by the lubricant properties. Particularly the viscosity is one of the main factors, which governs the overall system behaviour, affecting the drag torque and inertia of the idle gears, promoting rattle. This is an observation, which can contribute to root cause solutions of this NVH concern.

\section{ACKNOWLEDGEMENTS}

The authors wish to express their gratitude to Ford Motor Company and the EPSRC for the sponsorship and financial support extended to this research project. 


\section{APPENDIX A}

E Modulus of elasticity

$E^{\prime} \quad$ Reduced elastic modulus

L Length of contact

$P \quad$ Maximum pressure

$R \quad$ Equivalent radius of contact

W Load on contact

$\alpha \quad$ Contact semi-half width

$\delta \quad$ Contact deflection

$v \quad$ Poisson ration

The contact of a pair of teeth may be considered as an equivalent roller of radius $R$ and length $L$ contacting a semi-infinite elastic solid (i.e. the classic Hertzian theory). The contact deflection is obtained as:

$\delta=\frac{\alpha P}{E^{\prime}}\left\{\ln \left(\frac{2 L}{\alpha}\right)+\frac{1}{2}\right\}$

where, the contact semi-half width $\alpha$ is given as:

$\alpha=\left(\frac{8 W R}{\pi E^{\prime} L}\right)^{1 / 2}$

and the maximum pressure $P$ as:

$P=\frac{2 W}{\pi \alpha L}$

Using typical values: $W(17 N), R(\approx 0.008 m), L(\approx 0.01 m)$ and reduced elastic modulus: 
$E^{\prime}=\frac{E}{1-v^{2}}$

(for both bodies being of steel with $E=206 G P a$ and $v=0.3$ ), then $\delta$ becomes $\left(\approx 10^{-8} \mathrm{~m}\right)$, which is 2 orders of magnitude less than the lubricant film thickness. Thus, under idle rattle conditions iso-viscous rigid regime of lubrication is prevalent. 


\section{APPENDIX B}

$F_{f} \quad$ Flank friction

$h \quad$ Central film thickness

$L \quad$ Length of contact

$P \quad$ Pressure

$R \quad$ Equivalent radius of contact

$x \quad$ Dimension along the width of contact.

$x_{e} \quad$ Exit position

$x_{i} \quad$ Inlet position

Z Film thickness

$\Delta u \quad$ Sliding velocity/speed, $u_{1}-u_{2}$

Using half-Sommerfeld conditions (figure B1), the flank friction is given by:

$F_{f}=L \int_{x_{i}}^{x_{e}}\left[ \pm \frac{z \partial P}{2 \partial x}+\frac{\eta_{0} \Delta u}{z}\right] d x$

For low hydrodynamic pressures, the first term of equation (B1) can be neglected due to $\frac{z \partial P}{2 \partial x}<<\frac{\eta_{0} \Delta u}{z}$

Therefore, equation (B1) becomes

$F_{f}=L \int_{x_{i}}^{0}\left[\frac{\eta_{0} \Delta u}{z}\right] d x=L \eta_{0} \Delta u \int_{x_{i}}^{0}\left[\frac{1}{z}\right] d x$

Assuming an infinite hydrodynamic line contact (figure B2):

$Z=h_{0}\left(1+\frac{x^{2}}{2 R h_{0}}\right)$ 
By substituting (B3) into (B2):

$F_{f}=L \eta_{0} \Delta u \int_{x_{i}}^{0}\left[\frac{1}{h\left(1+\frac{x^{2}}{2 R h}\right)}\right] d x$

By substituting

$\tan \bar{x}=\frac{x}{\sqrt{2 R h}}$

and

$\sec ^{2} \bar{x} d \bar{x}=\frac{d x}{\sqrt{2 R h}}$

into (B4):

$F_{f}=\frac{L \eta_{0} \Delta u}{h} \sqrt{2 R h} \int_{x_{i}}^{0} d \bar{x}=-\frac{\eta_{0} \Delta u}{\sqrt{h}} \sqrt{2 R} \bar{x}_{i}$

Substituting equation (B5) again into (B7)

$F_{f}=-\frac{L \eta_{0} \Delta u}{\sqrt{h}} \sqrt{2 R} \tan ^{-1}\left(\frac{x_{i}}{\sqrt{2 R h}}\right)$

Assuming fully flooded conditions

$x_{i} \rightarrow-\infty$

$\tan ^{-1}(-\infty) \rightarrow \frac{-\pi}{2}$

$F_{f}=\frac{L \pi \eta_{0} \Delta u}{\sqrt{2 h}} \sqrt{R}$

During gearing action, $\Delta u$ is the sliding velocity of the meshing teeth surfaces (or $u_{s}$ ), which changes direction as the contact crosses the pitch point. This leads to a negative value for friction, which when substituted into the equations of motion yields forcing 
terms rather than dissipative terms, contravening the concept of friction. To correct this malfunction of (B11) and achieving a dissipative hydrodynamic friction force, the sliding velocity $u_{s}$ has been replaced by

$$
F_{f}=\left\{\begin{array}{cc}
\frac{L \pi \eta_{0} u_{s}}{\sqrt{2 h}} \sqrt{R}, & u_{s}>0 \\
\frac{L \pi \eta_{0}\left(-u_{s}\right)}{\sqrt{2 h}} \sqrt{R}, & u_{s}<0
\end{array}\right.
$$

according to the reported validated approach by (Vaishya and Singh [38] and [39]).

With no lateral degrees of freedom considered for the transmission shafts (the current model is only torsional), any resulting significant convergence of mating members (large squeeze film effect) is ignored. Thus, the effect of hydrodynamic pressures on friction have been considered to be small compared to that due to relative sliding velocity as already pointed out above. This amounts to an assumption, which may not be inherently correct, as there are lateral rigid body oscillations of the transmission shafts, as well as their likely bending. 


\section{REFERENCES}

[1] T. Sakai, Y. Doi, K. Yamamoto, T. Ogasawara, M. Narita, Theoretical and Experimental Analysis of Rattling Noise of Automotive Gearbox, SAE Technical Paper 810773 (1981), pp. 1-10.

[2] S. N. Dogan, G. Lechner, Maßnahmen zur Verringerung von Losteilschwingungen in Fahrzeuggetrieben, ATZ Autombiltechnische Zeitschrift 100 (1998) 10, pp. 710-716.

[3] M. Wang, R. Manoj, and W. Zhao, Gear Rattle Modelling and Analysis for Automotive Manual Transmissions, Proceedings of the IMechE Part D: Journal of Automobile Engineering (2001), 215 pp. 241-258.

[4] R. Seaman, C. Johnson, and R. Hamilton, Component Inertial Effects on Transmission Design, SAE Technical Paper 841686 (1984), pp. 6.990-6.1008.

[5] T. Fujimoto, Y. Chikatani, and J. Kojima, Reduction of Idling Rattle in Manual Transmission, SAE Technical Paper 870395 (1987), pp. 2.99-2.109.

[6] T. Fujimoto, and T. Kizuka, An Improvement of the Prediction Method of the Idling Rattle in Manual Transmission- In the Case of the Manual Transmission with Backlash Eliminator-, SAE Technical Paper 2001-01-1164, 2001.

[7] O. Johnson and N. Hirami, Diagnosis and Objective Evaluation of Gear Rattle, SAE Technical Paper 911082 (1991), pp. 1547-1562.

[8] E. I. Rivin, Analysis and Reduction of Rattling in Power Transmission Systems, SAE Technical Paper 2000-01-0032, 2000.

[9] R. Gohar, Elastohydrodynamics, Imperial College Press, 2001, $2^{\text {nd }}$ edition. 
[10] M. Gnanakumarr, S. Theodossiades, and H. Rahnejat, The Tribo-Contact Dynamics Phenomenon in Torsional Impact Of Loose Gears - Promoting Gear Rattle, SAE 02ATT138, Society of Automotive Engineers (SAE)-ATT Congress, Paris, 2002.

[11] G. Fudala, T. Engle and A. Karvelis. A System Approach to Reducing Gear Rattle, SAE Technical Paper 870396 (1987), pp.2.110-2.117.

[12] S. Theodossiades, M. Gnanakumarr, H. Rahnejat, and P. Kelly, On the Effect Dual Mass Flywheel Upon Impact Induced Noise in Vehicular Powertrain Systems. Proceedings of the IMechE Part D: Journal of Automobile Engineering (2006) 220(6), pp. 747-761.

[13] T.C. Kim, R. Singh, Dynamic Interactions between Loaded and Unloaded Gear Pairs under Rattle Conditions, SAE Technical Paper 2001-01-1553 (2001), pp.1934-1943.

[14] P. Bellomo, F. Cricenti, N. De Vito, C. Lang, and D. Minervini, Innovative Vehicle Powertrain Systems Engineering: Beating the Noisy Offenders in Vehicle Transmissions, SAE Technical Paper 2000-01-0033, 2000.

[15] J. Biermann, B. Hagerodt, Investigation of the Clonk Phenomenon in Vehicle Transmissions- Measurement, Modelling and Simulation, Proceedings of the IMechE Part K (1999) 213, pp. 53-60.

[16] T. Fujimoto, and T. Kizuka, Predictive Calculation of Idling Rattle in Manual Transmissions -Based on Experimental Measurements of Gear Vibration Occurring in Backlashes-“, SAE Technical Paper 2003-01-0678, 2003.

[17] R. Singh, H. Xie, and R. Comparin, Analysis of Automotive Neutral Gear Rattle, Journal of Sound and Vibration (1989), pp. 177-196. 
[18] T. Fujimoto, and T. Kizuka, Audible Noise Simulation -an Attempt to Predict Idling Rattle in Manual Transmissions-, SAE Technical Paper 2003-01-0674, 2003.

[19] S. Meisner, B. Campbell, Development of Gear Rattle Analytical Simulation Methodology, SAE Technical Paper 951317 (1995), pp. 2344-2353.

[20] A. Kahraman and R. Singh, Interactions between Time-Varying Mesh Stiffness and Clearance Non-Linearities in a Geared System, Journal of Sound and Vibration (1991) 146(1), pp 135-156.

[21] G. Blankenship and R. Singh, A New Gear Mesh Interface Dynamic Model to Predict Multi-Dimensional Force Coupling and Excitation, Mech. Mach. Theory (1995) vol. 30 No. 1, pp. 43-57.

[22] M. Wang, W. Zhao, and R. Manoj, Numerical Modelling and Analysis of Automotive Transmission Rattle, Journal of Vibration and Control 8 (2002), pp. 921-943.

[23] R. Yakoub, M. Corrado, A. Forcelli, T. Pappalardo, and S. Dutre, Prediction of System-Level Gear Rattle Using Multibody and Vibro-Acoustic Techniques, SAE Technical Paper 2004-32-0063/20044350, 2004.

[24] S. Theodossiades and S. Natsiavas, Non-Linear Dynamics of Gear-Pair Systems with Periodic Stiffness and Backlash, Journal of Sound and Vibration (2000), 229(2), pp. 287310.

[25] S. Theodossiades and S. Natsiavas, On Geared Rotordynamic Systems with Oil Journal Bearings, Journal of Sound and Vibration (2001), 243(4), pp. 721-745.

[26] H. Rahnejat, The Influence of Vibration on the Oil film in Elasto-hydrodynamic Contacts, PhD Thesis, Imperial College, University of London, 1984. 
[27] O. Tangasawi, S. Theodossiades, H. Rahnejat, P. Kelly, Gear Teeth Impact Dynamics in Manual Transmissions Promoting Idle Rattle, Proceedings of the $5^{\text {th }}$ EUROMECH Nonlinear Dynamics Conference, Eindhoven, 2005.

[28] H. Merritt, Gear Engineering, Pitman Publishing, 1971.

[29] A. Kahraman, D. R. Houser, and H. Xu, Development of a Generalized Mechanical Efficiency Prediction Methodology for Gear Pairs, Year 1 Progress Report submitted to AGMA Foundations, The Ohio State University, 2005.

[30] T. Sasaki, H. Mori and N. Okino, Fluid Lubrication Theory of Roller Bearings, Trans. ASME, J. Basic Engineering, 1962.

[31] R. Graikousis, Machine Elements, Vol. 3, $2^{\text {nd }}$ Edition, Greece, 1985 (in Greek).

[32] B. Hamrock, S. Schmid, and B. Jacobson, Fundamentals of Fluid Film Lubrication, Marcel Dekker Inc., $2^{\text {nd }}$ edition, 2004.

[33] R. Taylor, Engine Friction: The Influence of Lubrication Rheology, Proceedings of the IMechE Part J (1997), Volume 211, pp. 235-246.

[34] S. Timoshenko, D. H. Young, and W. Weaver Jr., Vibration problems in Engineering, John Wiley \& Sons, $4^{\text {th }}$ Edition, 1974.

[35] R. J. Comparin, and R. Singh, An Analytical Study of Automotive Neutral Gear Rattle, Journal of Mechanical Design (1990), vol. 112, pp. 237-245.

[36] H. Rahnejat, Multi-body Dynamics: Vehicles, Machines and Mechanisms, Copublishers: PEP (IMechE) Bury St Edmonds and SAE, Warrendale, 1998.

[37] Auto Signal Version 1.7 User’s Manual, Seasolve, Richmond, CA, USA, 2003.

[38] M. Vaishya and R. Singh, Strategies for Modelling Friction in Gear Dynamics, Journal of Mechanical Design (2003), 125, 383-393. 
[39] M. Vaishya and R. Singh, Sliding Friction-Induced Non-linearity and Parametric Effects in Gear Dynamics, Journal of Sound and Vibration (2001), 248(4), 671-694. 


\section{FIGURE CAPTIONS}

Figure 1: Front Wheel Drive Transmission Layout

Figure 2: Gear Teeth Rolling Action.

Figure 3: Contact Lines and Hydrodynamic Friction on Tooth Flank.

Figure 4: Hydrodynamic Reaction and Friction Forces

Figure 5: Hydrodynamic Reaction and Petrov’s Force.

Figure 6: Computational Flowchart

Figure 7: FFT Spectrum of the Transmission Input Shaft Measured Torsional Oscillations

Figure 8: Time Histories of $\ddot{\varphi}$ for (a) $1^{\text {st }}$ Gear, (b) $2^{\text {nd }}$ Gear, (c) $3^{\text {rd }}$ Gear, (d) $4^{\text {th }}$ Gear, (e) $5^{\text {th }}$ Gear, (f) $6^{\text {th }}$ Gear and (g) Reverse Gear.

Figure 9: Time Histories of $h$ for (a) $1^{\text {st }}$ Gear, (b) $2^{\text {nd }}$ Gear, (c) $3^{\text {rd }}$ Gear, (d) $4^{\text {th }}$ Gear, (e) $5^{\text {th }}$ Gear, (f) $6^{\text {th }}$ Gear and (g) Reverse Gear.

Figure 10: FFT Spectra of $h$ for (a) $1^{\text {st }}$ Gear, (b) $2^{\text {nd }}$ Gear, (c) $3^{\text {rd }}$ Gear, (d) $4^{\text {th }}$ Gear, (e) $5^{\text {th }}$ Gear, (f) $6^{\text {th }}$ Gear and (g) Reverse Gear.

Figure 11: AR Spectra of $\ddot{\varphi}$ for (a) $1^{\text {st }}$ Gear, (b) $2^{\text {nd }}$ Gear, (c) $3^{\text {rd }}$ Gear, (d) $4^{\text {th }}$ Gear, (e) $5^{\text {th }}$ Gear, (f) $6^{\text {th }}$ Gear and (g) Reverse Gear.

Figure 12: Natural Frequencies and Mode Shapes of the Linearised System. Vertical axes in all figures refers to the predicted amplitude of normalised modes

Figure 13: AR Spectra of $\ddot{\varphi}$, corresponding to $20^{\circ} \mathrm{C}$ Lubricant Viscosity for (a) $1^{\text {st }}$ Gear, (b) $2^{\text {nd }}$ Gear, (c) $3^{\text {rd }}$ Gear, (d) $4^{\text {th }}$ Gear, (e) $5^{\text {th }}$ Gear, (f) $6^{\text {th }}$ Gear and (g) Reverse Gear.

Figure 14: RMS Values of $\ddot{\varphi}$ with respect to Temperature for (a) $1^{\text {st }}$ Gear, (b) $2^{\text {nd }}$ Gear, (c) $4^{\text {th }}$ Gear and (d) Reverse Gear.

Figure B1: Half-Sommerfeld Conditions.

Figure B2: Film Shape in Hydrodynamic Infinite Line Contact. 


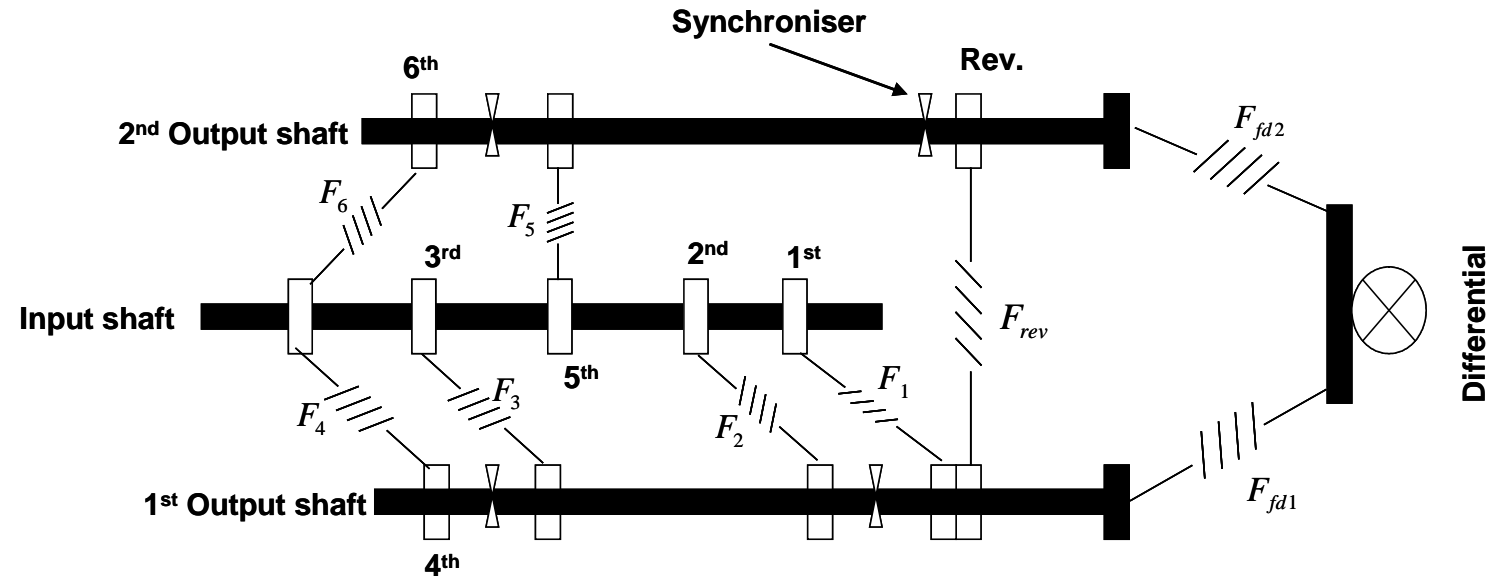

Figure 1: Front Wheel Drive Transmission Layout.

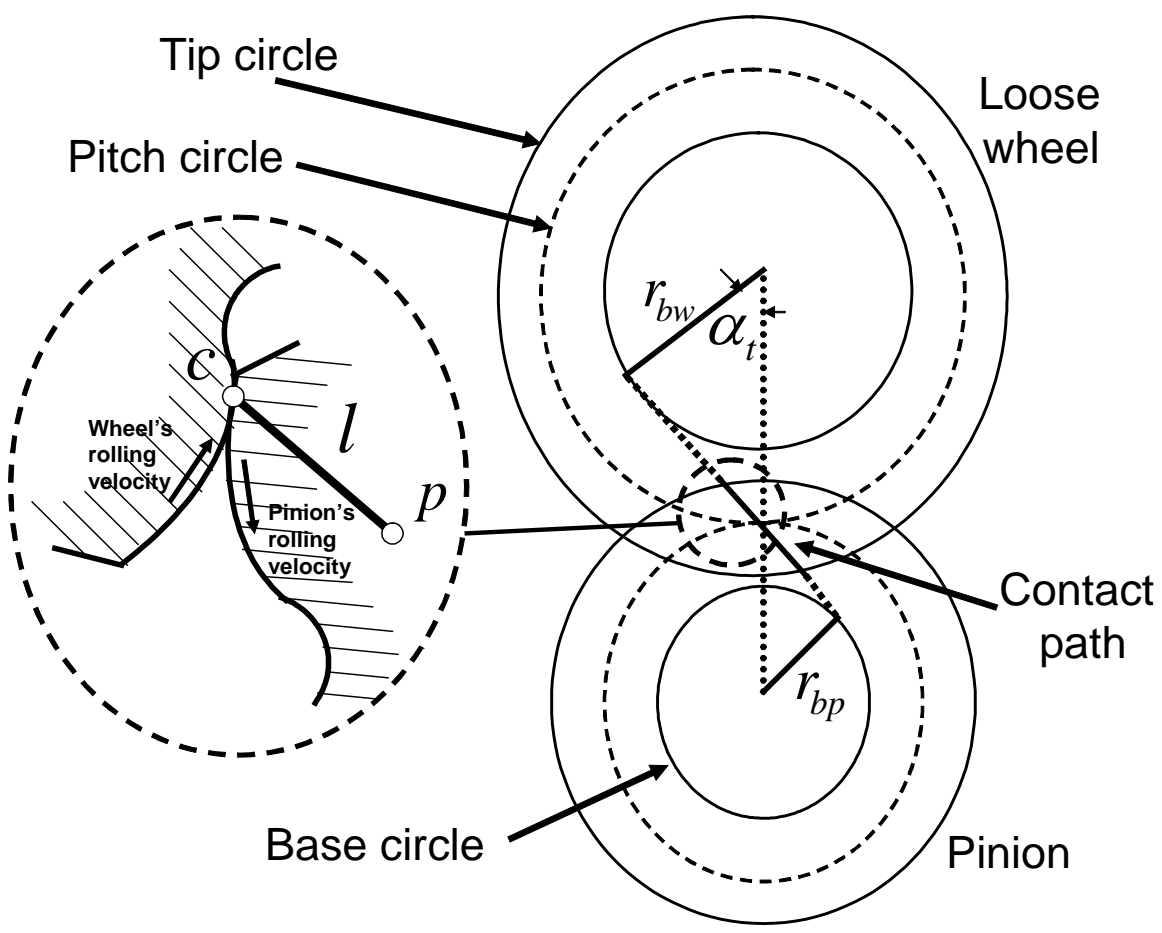

Figure 2: Gear Teeth Rolling Action. 
(a)

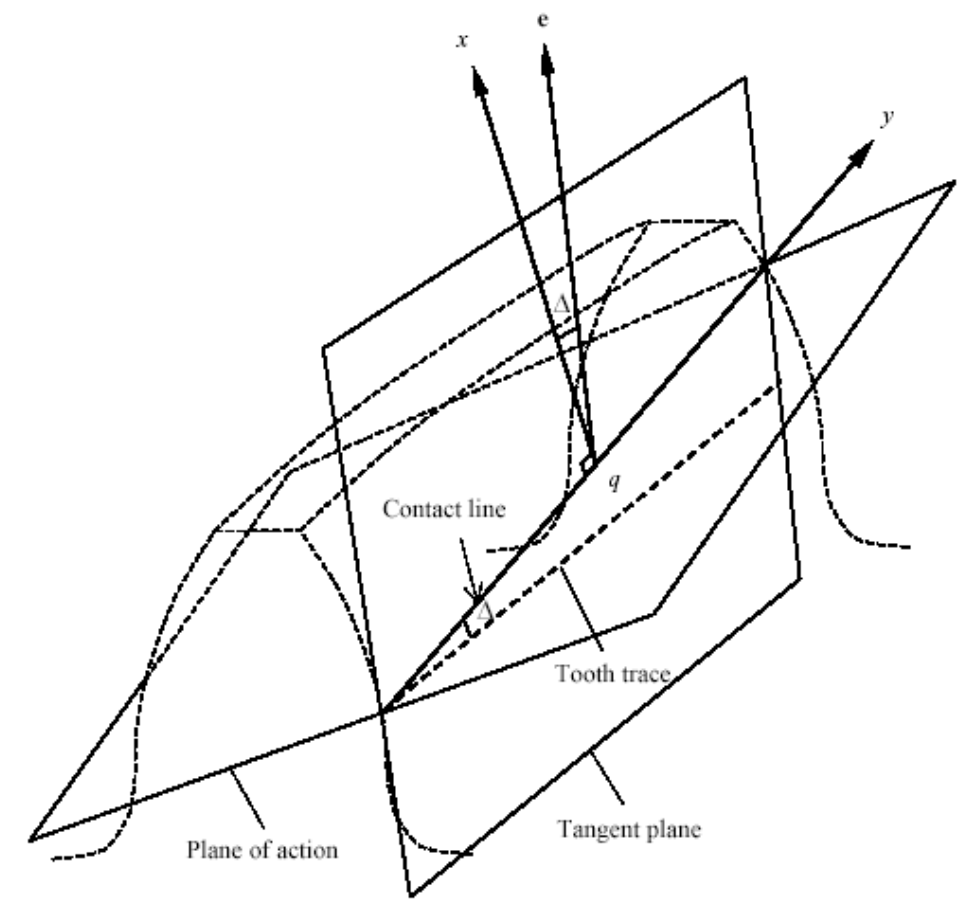

(b)

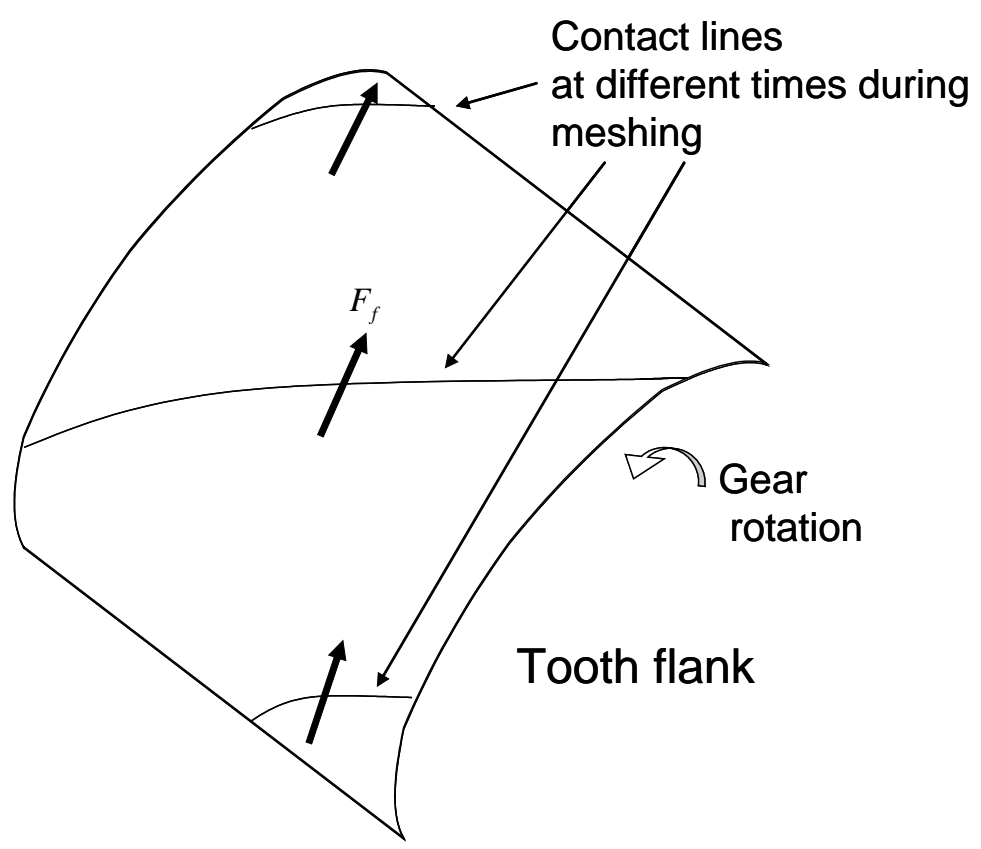

Figure 3: Contact Lines and Hydrodynamic Friction on Tooth Flank [29]. 

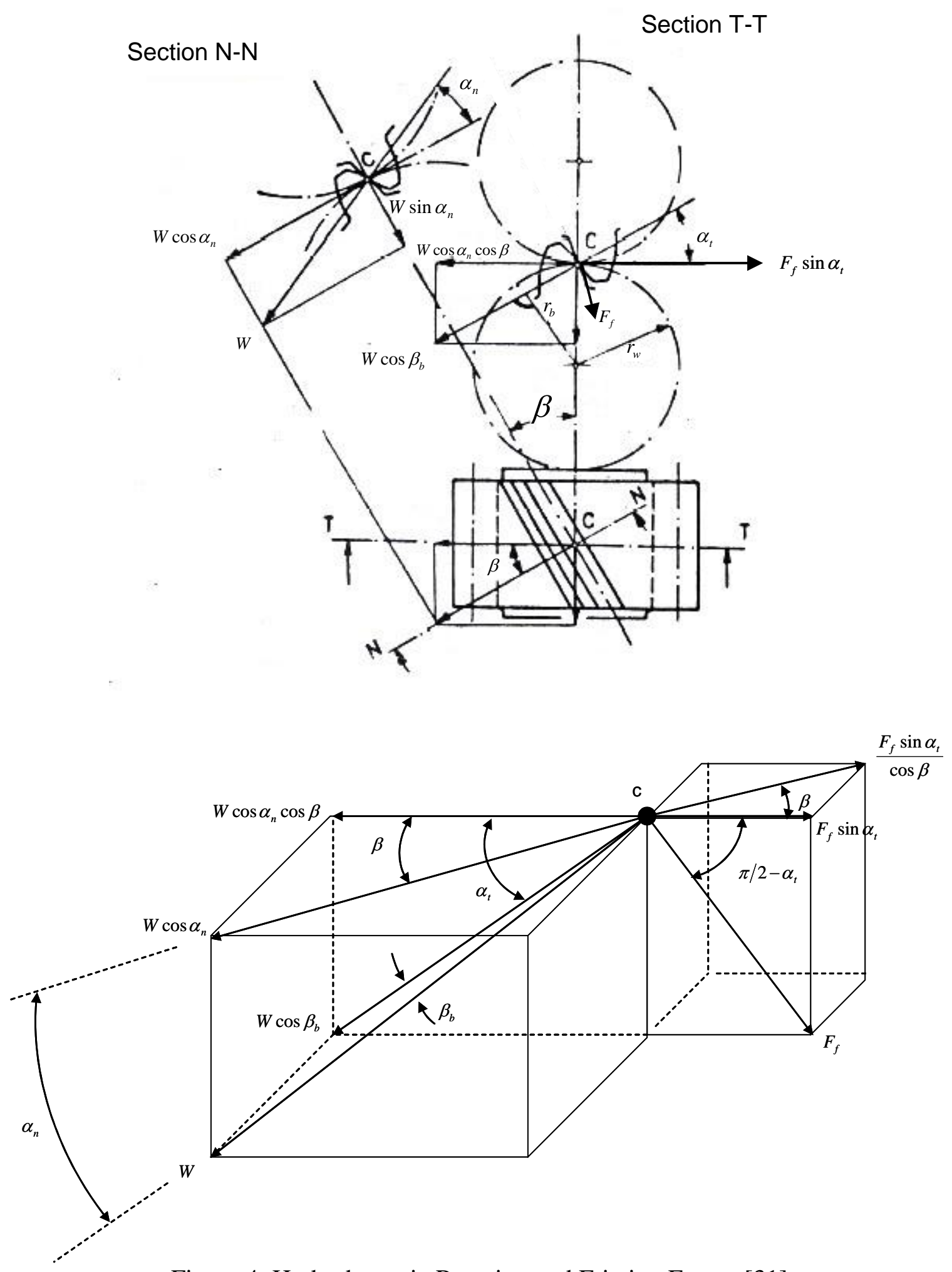

Figure 4: Hydrodynamic Reaction and Friction Forces [31] 


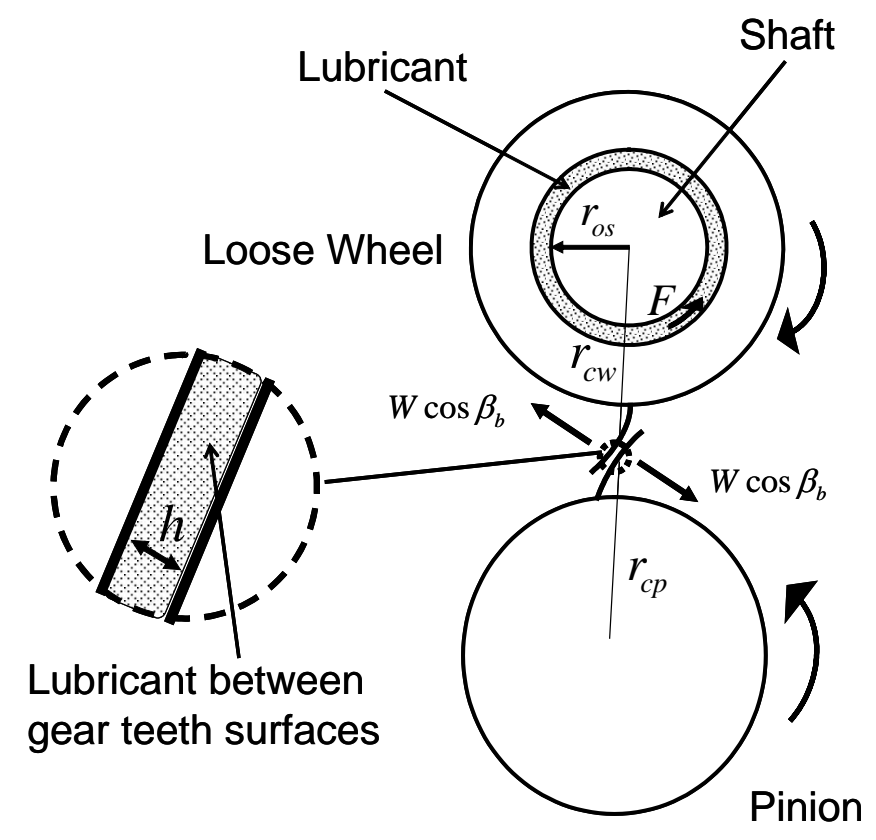

Figure 5: Hydrodynamic Reaction and Petrov’s Force. 


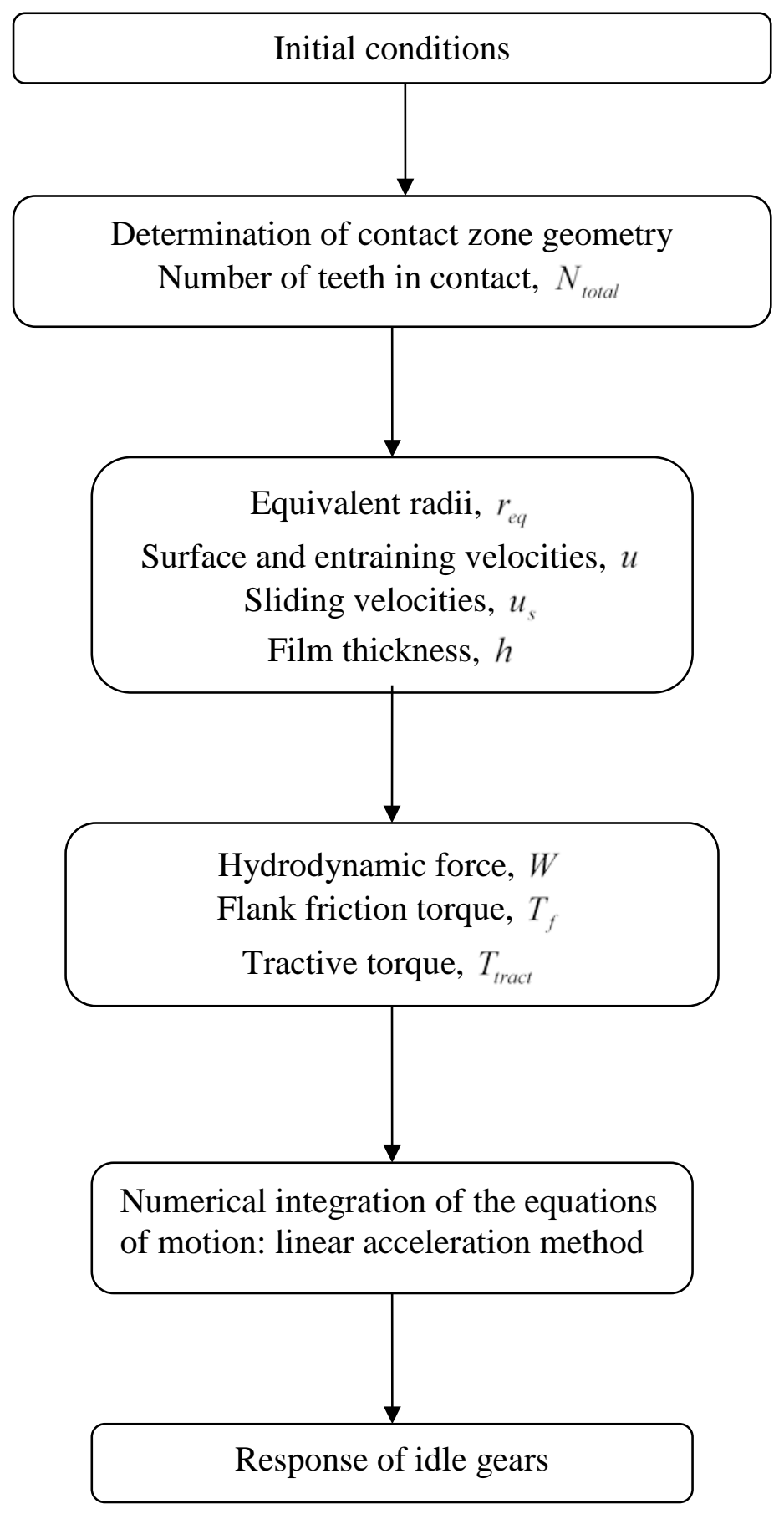

Figure 6: Computational Flowchart. 


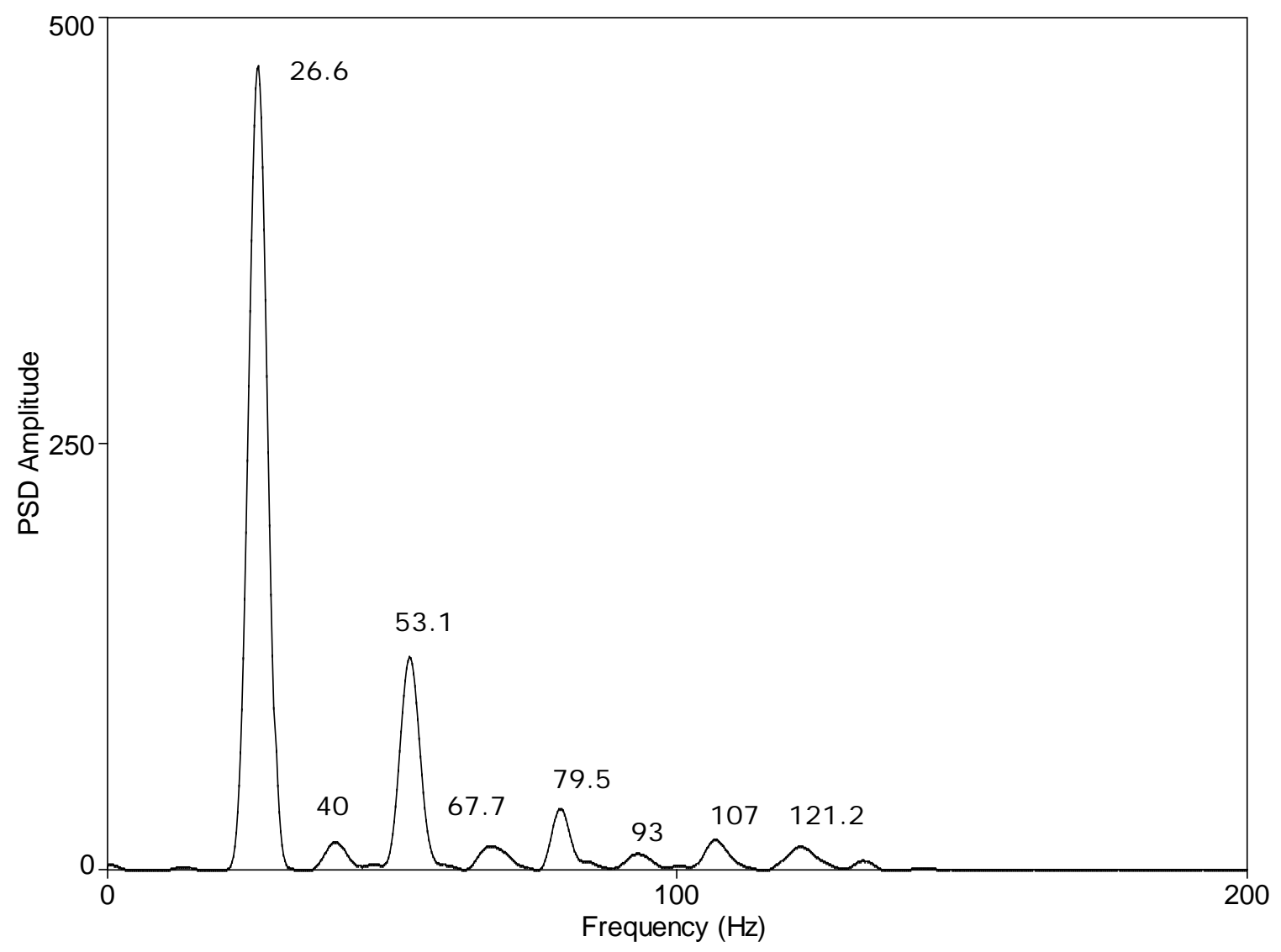

Figure 7: FFT Spectrum of the Transmission Input Shaft Measured Torsional Oscillations 

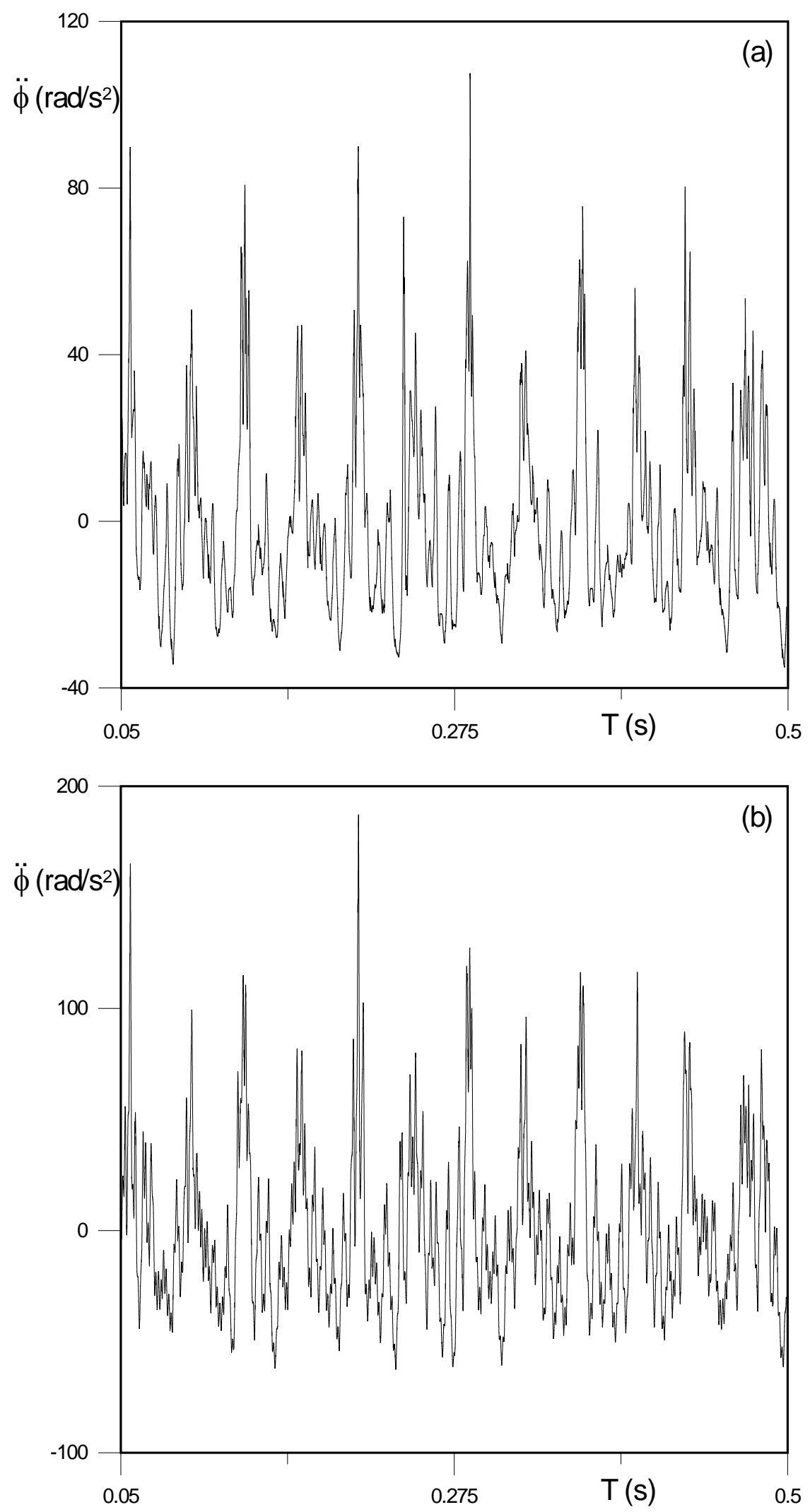

Figure 8 (continued over) 

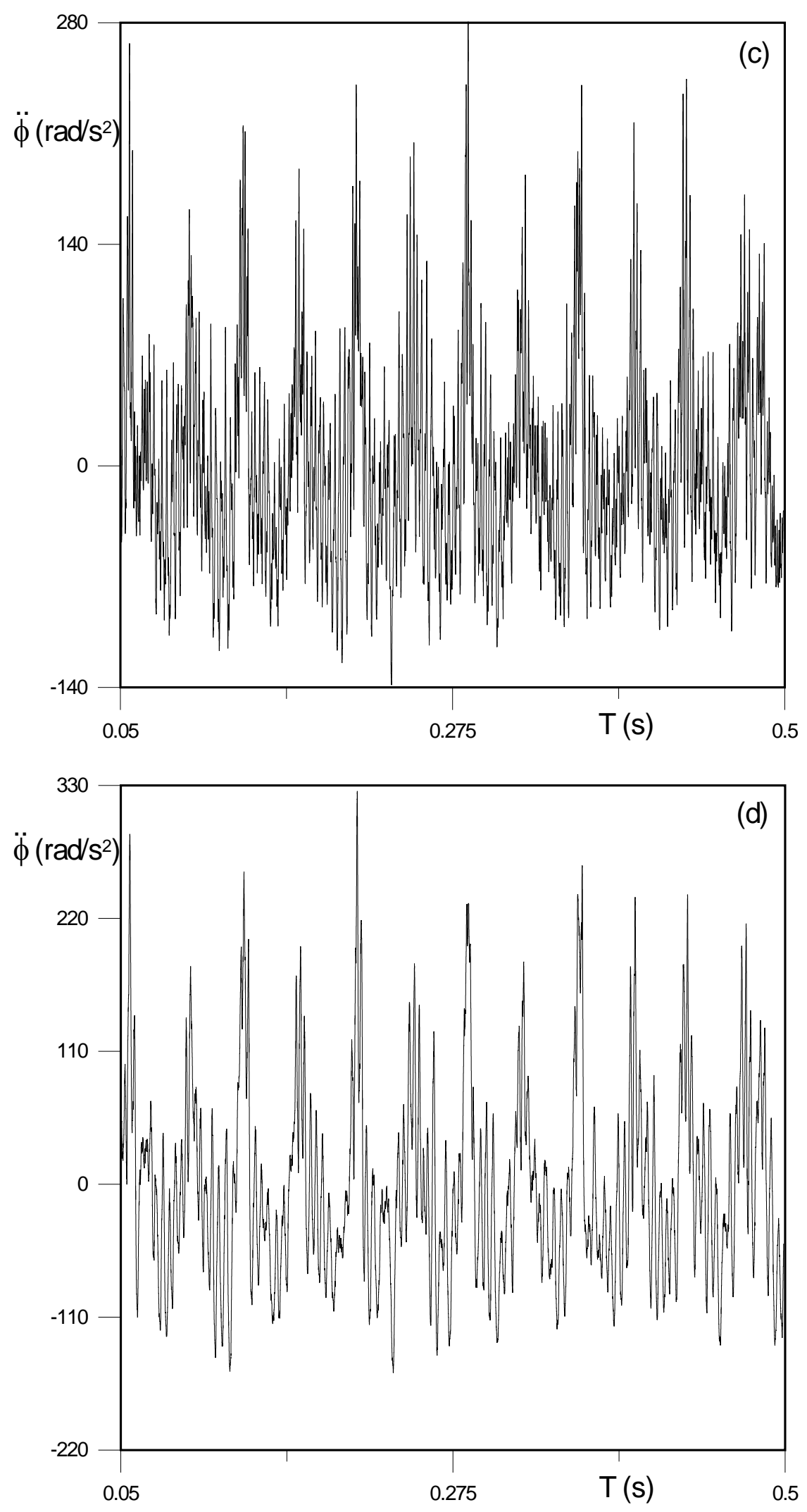

Figure 8 (continued over) 

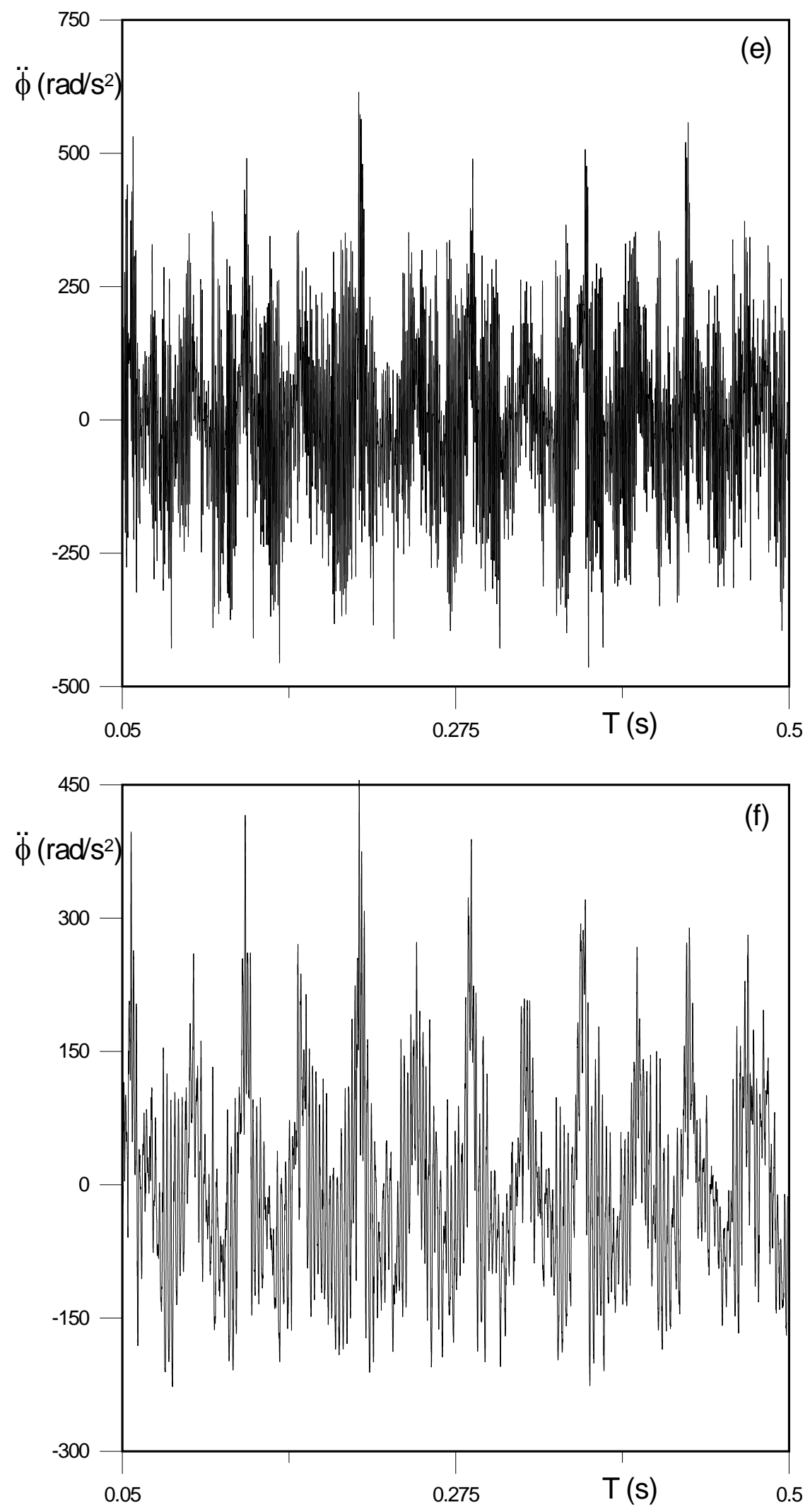

Figure 8 (continued over) 


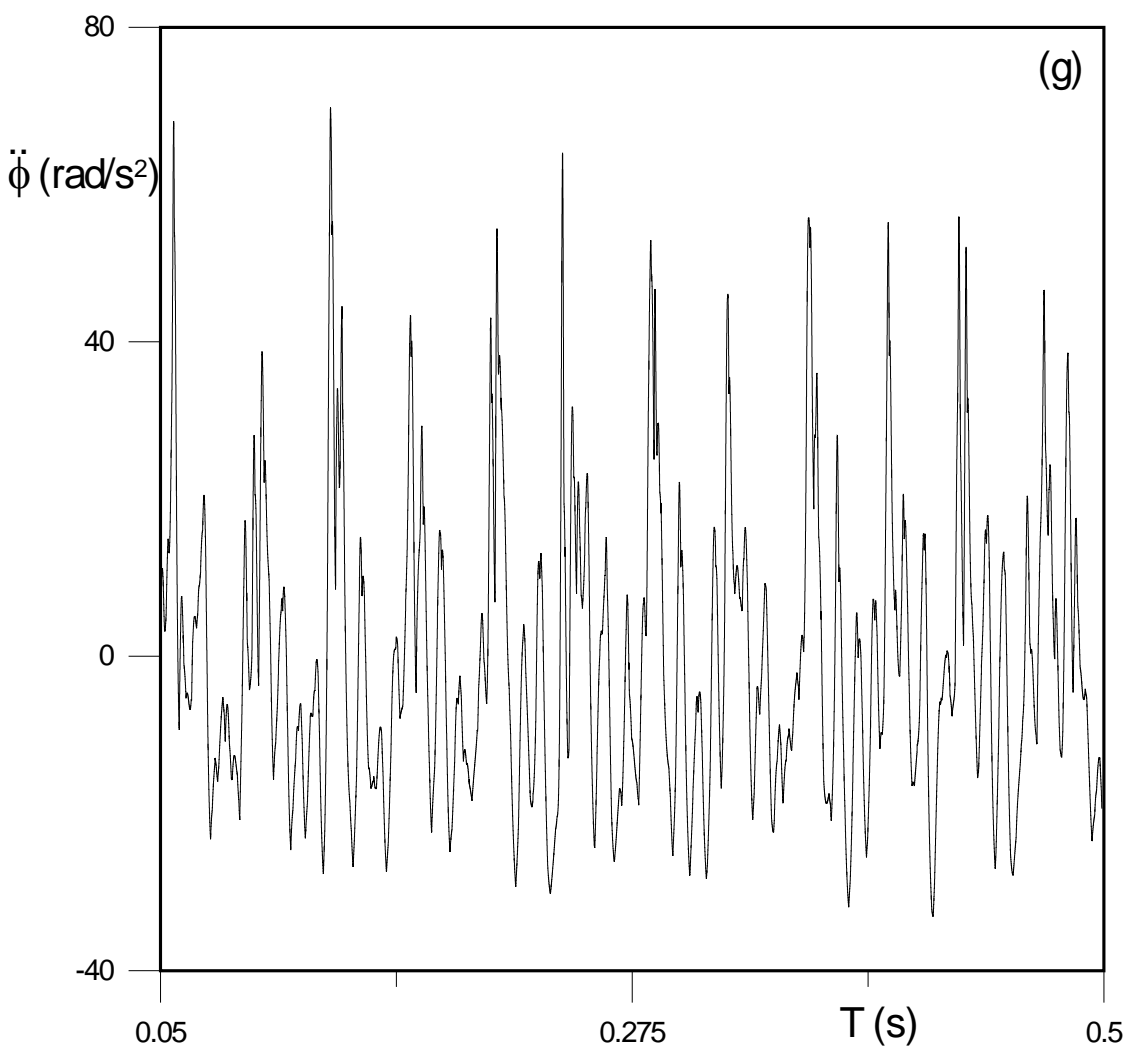

Figure 8: Time Histories of $\ddot{\varphi}$ for (a) $1^{\text {st }}$ Gear, (b) $2^{\text {nd }}$ Gear, (c) $3^{\text {rd }}$ Gear, (d) $4^{\text {th }}$ Gear, (e) $5^{\text {th }}$ Gear, (f) $6^{\text {th }}$ Gear and (g) Reverse Gear. 

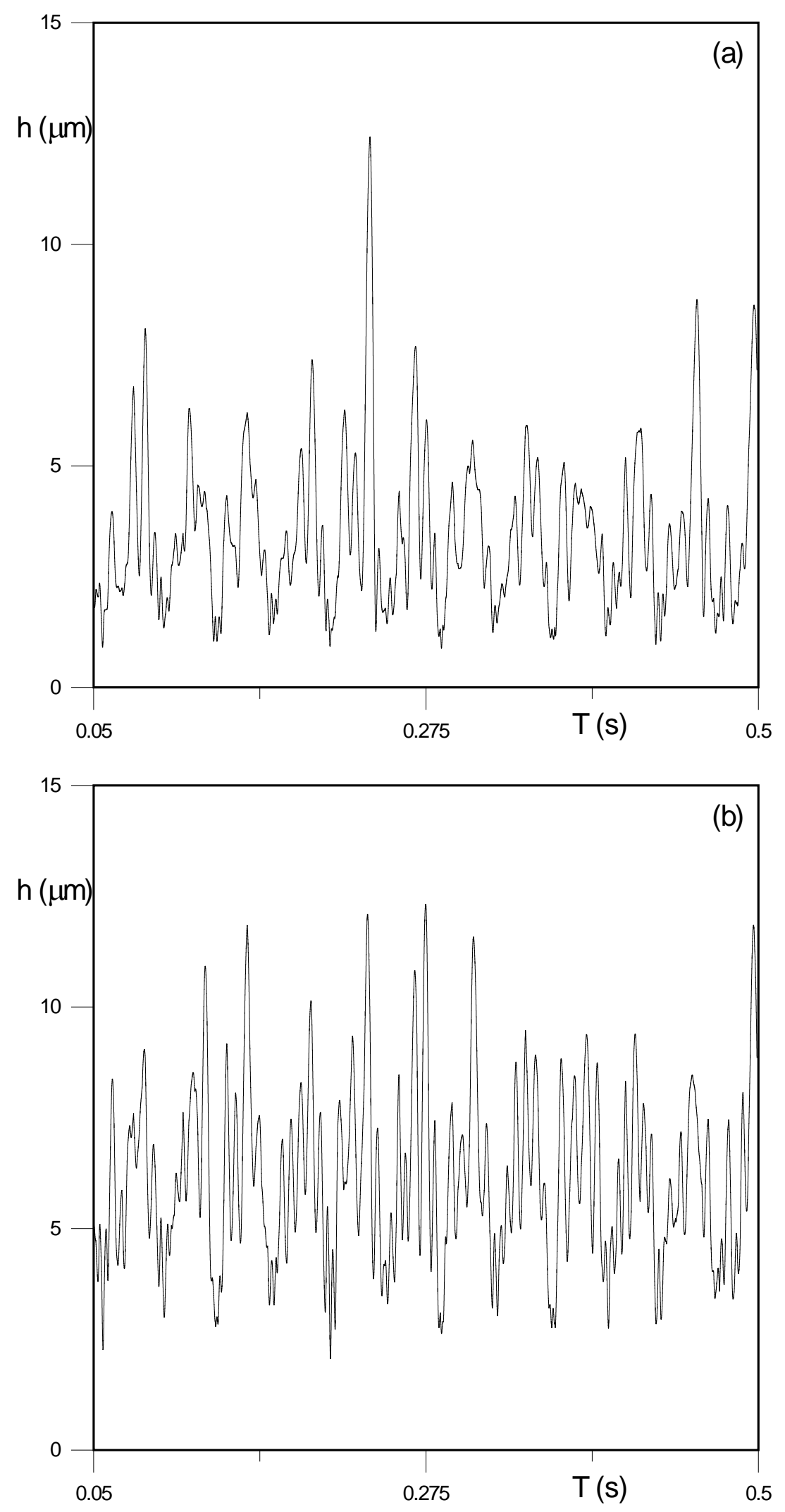

Figure 9 (continued over) 

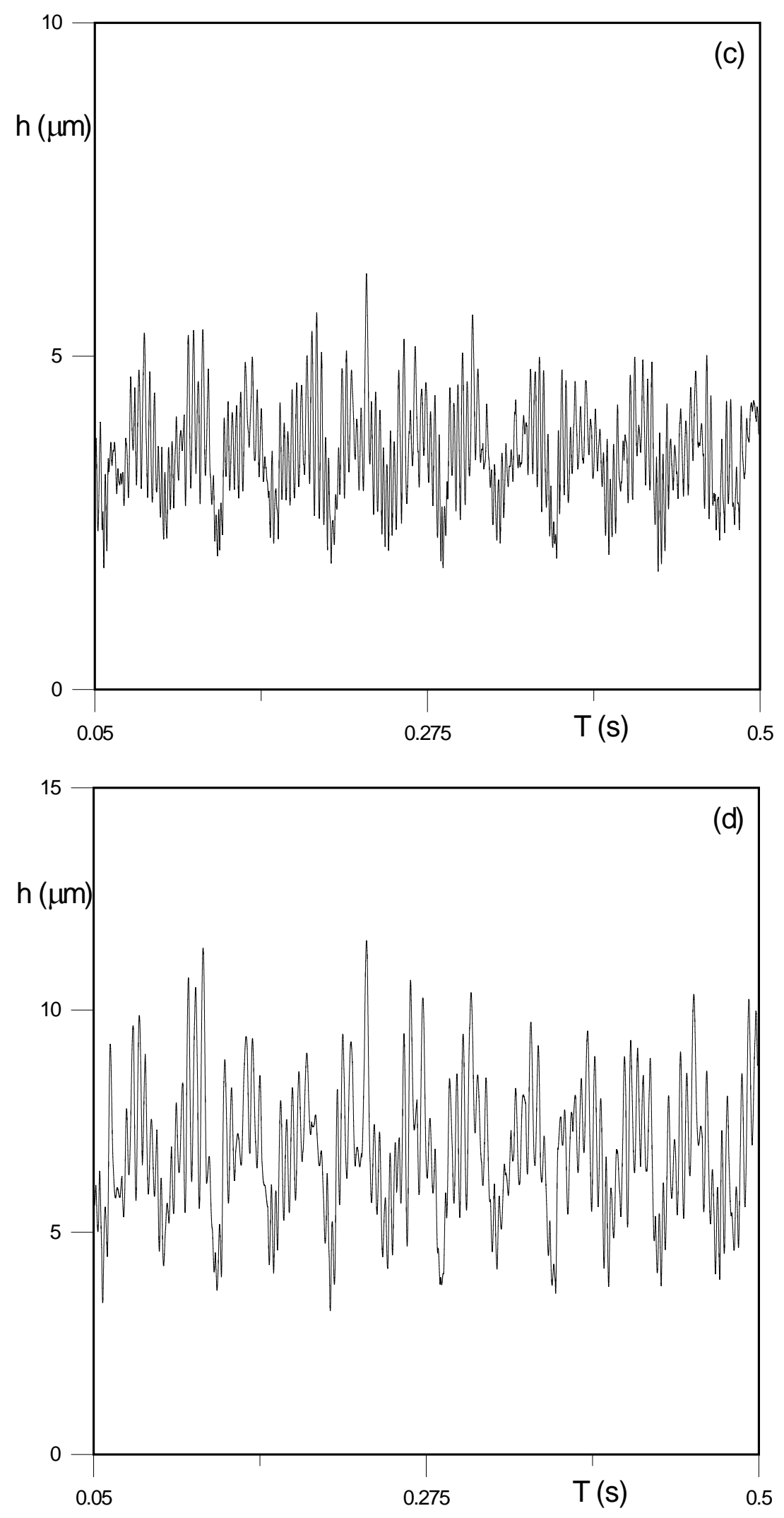

Figure 9 (continued over) 

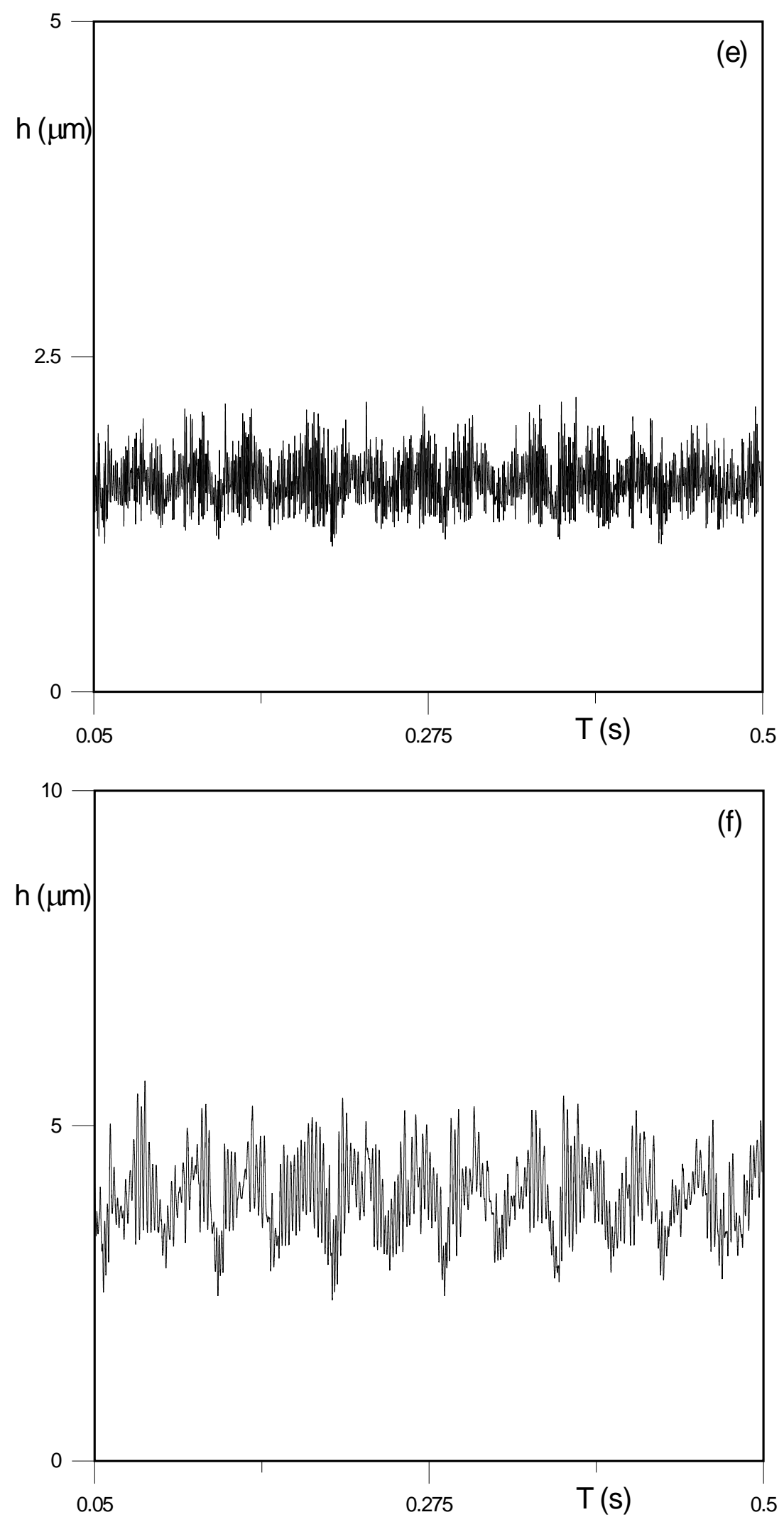

Figure 9 (continued over) 


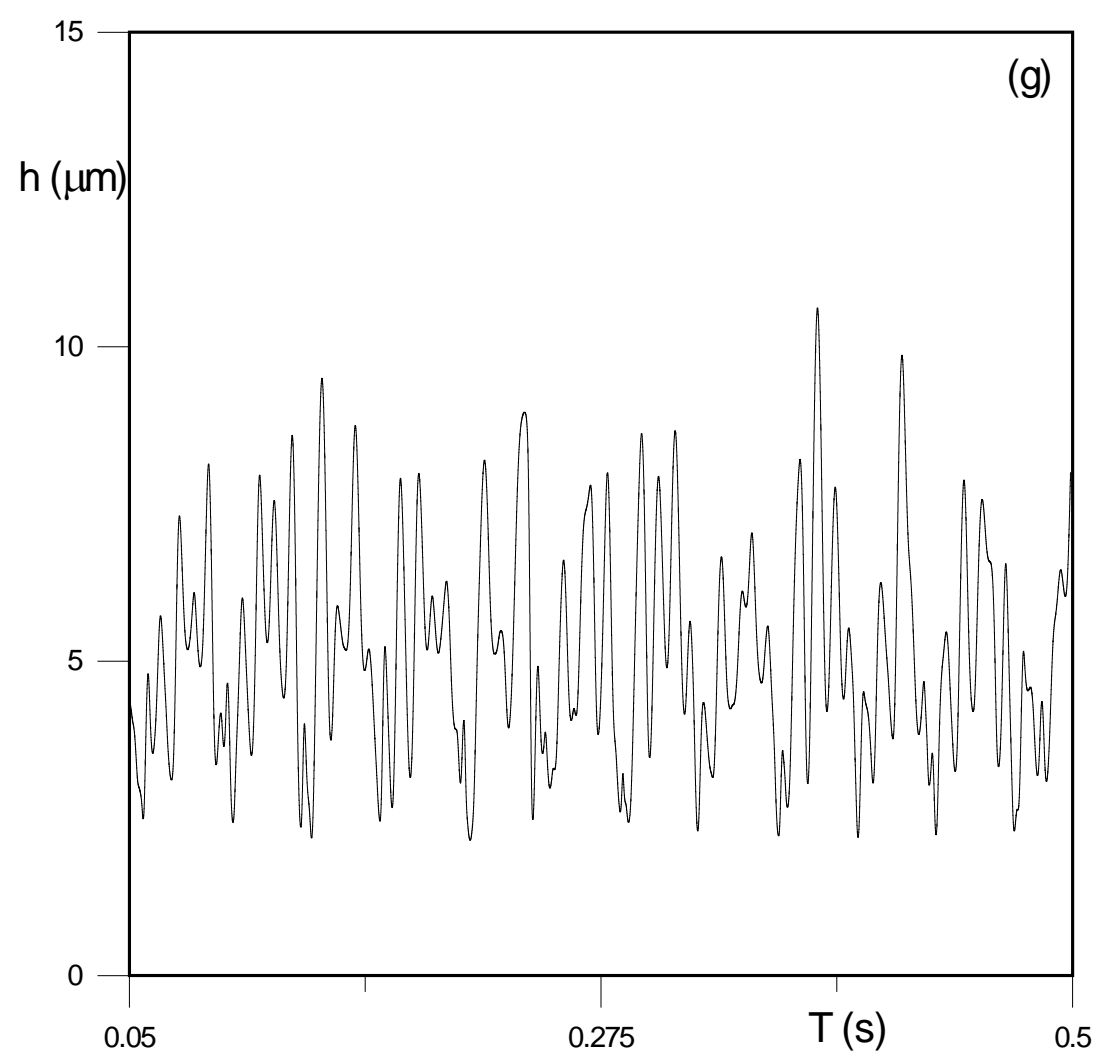

Figure 9: Time Histories of $h$ for (a) $1^{\text {st }}$ Gear, (b) $2^{\text {nd }}$ Gear, (c) $3^{\text {rd }}$ Gear, (d) $4^{\text {th }}$ Gear, (e) $5^{\text {th }}$ Gear, (f) $6^{\text {th }}$ Gear and (g) Reverse Gear. 

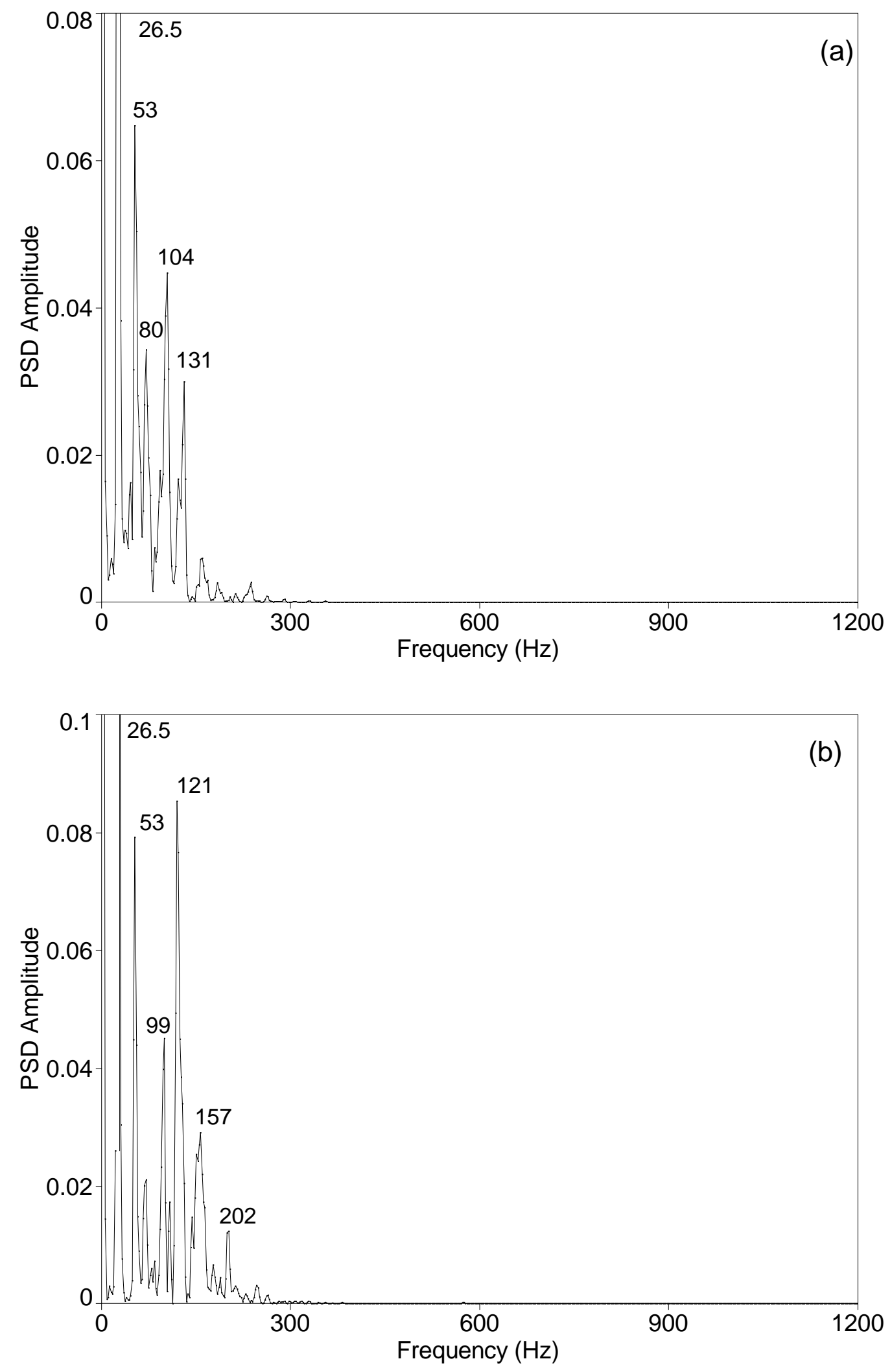

Figure 10 (continued over) 

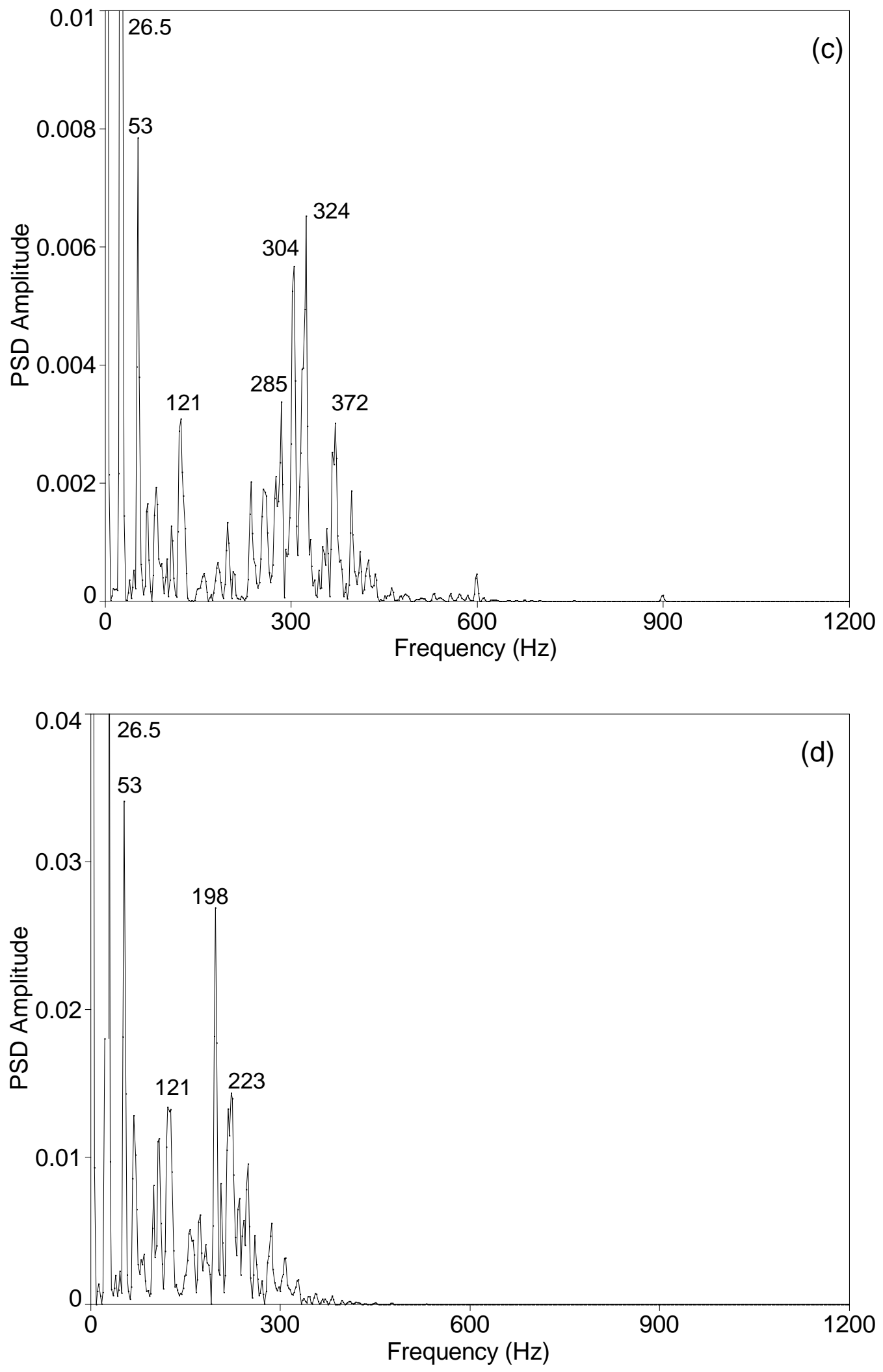

Figure 10 (continued over) 

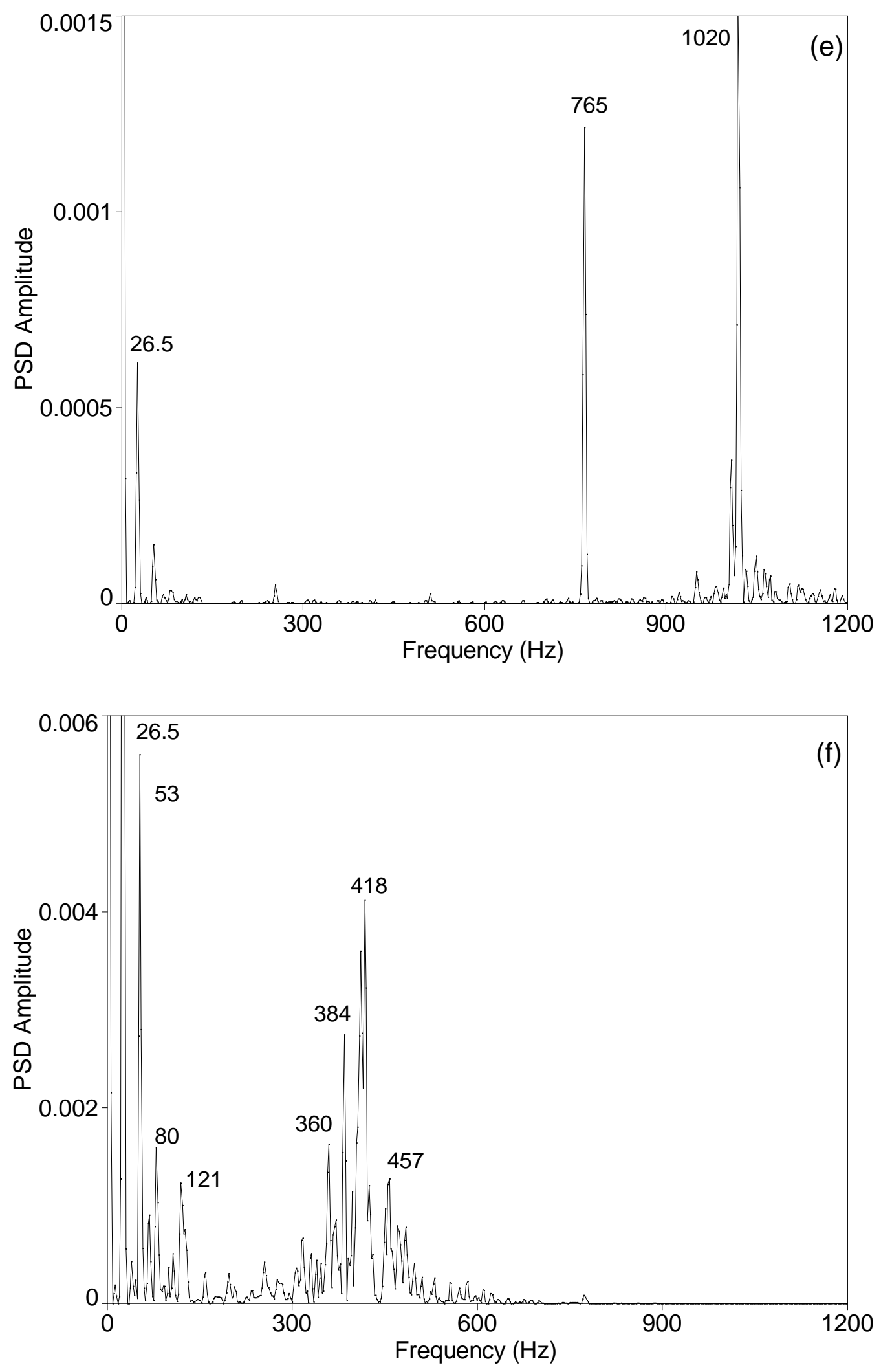

Figure 10 (continued over) 


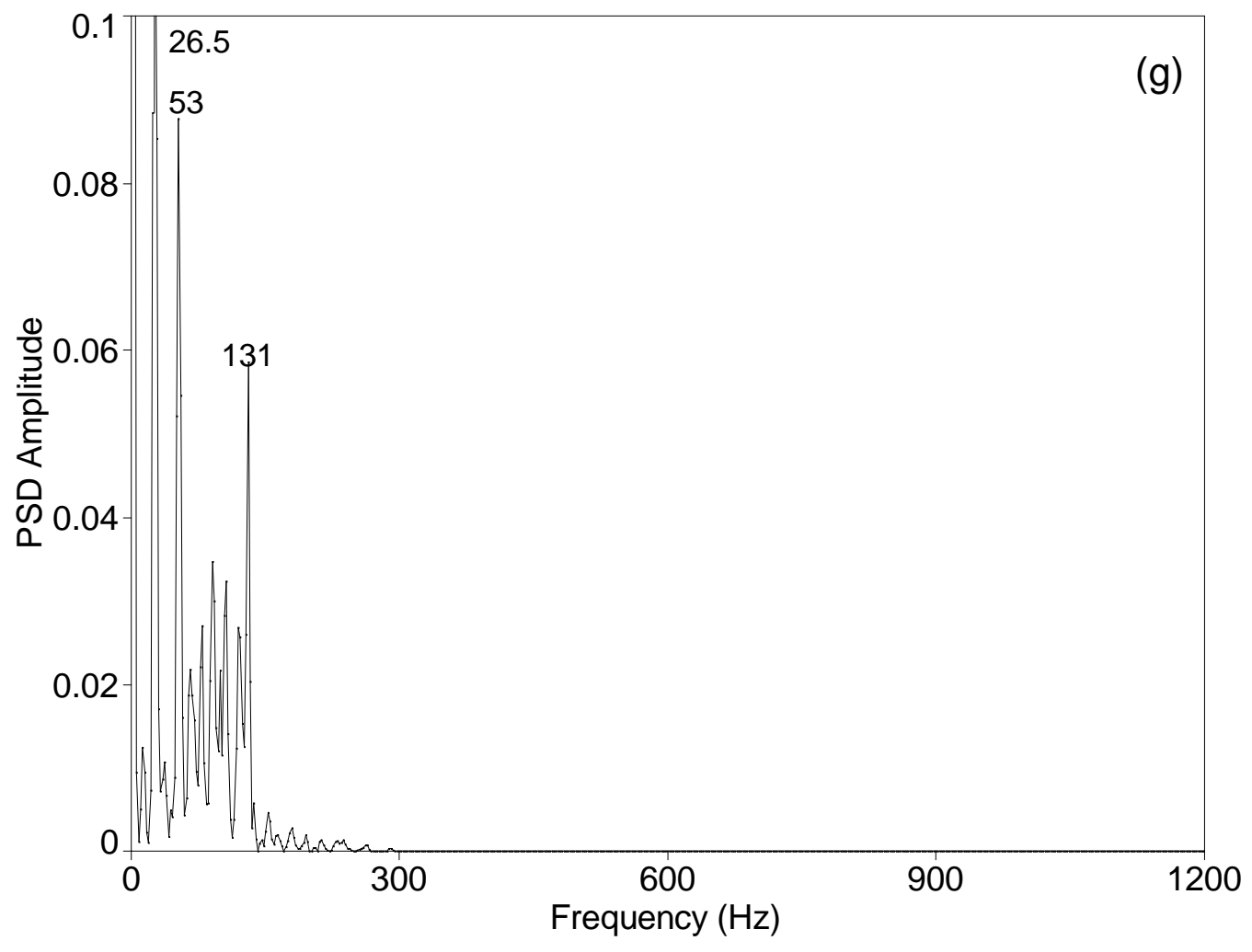

Figure 10: FFT Spectra of $h$ for (a) $1^{\text {st }}$ Gear, (b) $2^{\text {nd }}$ Gear, (c) $3^{\text {rd }}$ Gear, (d) $4^{\text {th }}$ Gear, (e) $5^{\text {th }}$ Gear, (f) $6^{\text {th }}$ Gear and (g) Reverse Gear. 

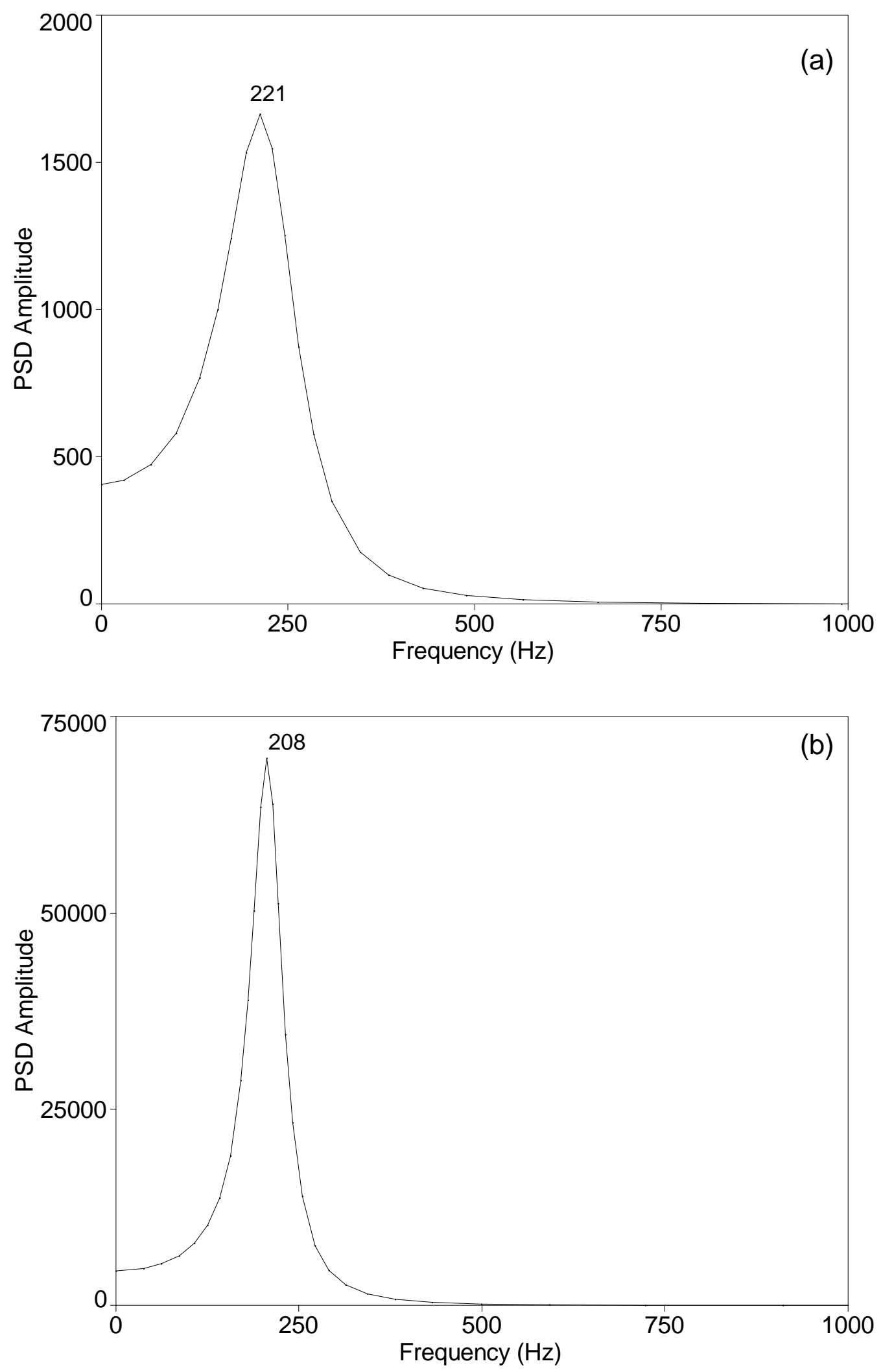

Figure 11 (continued over) 

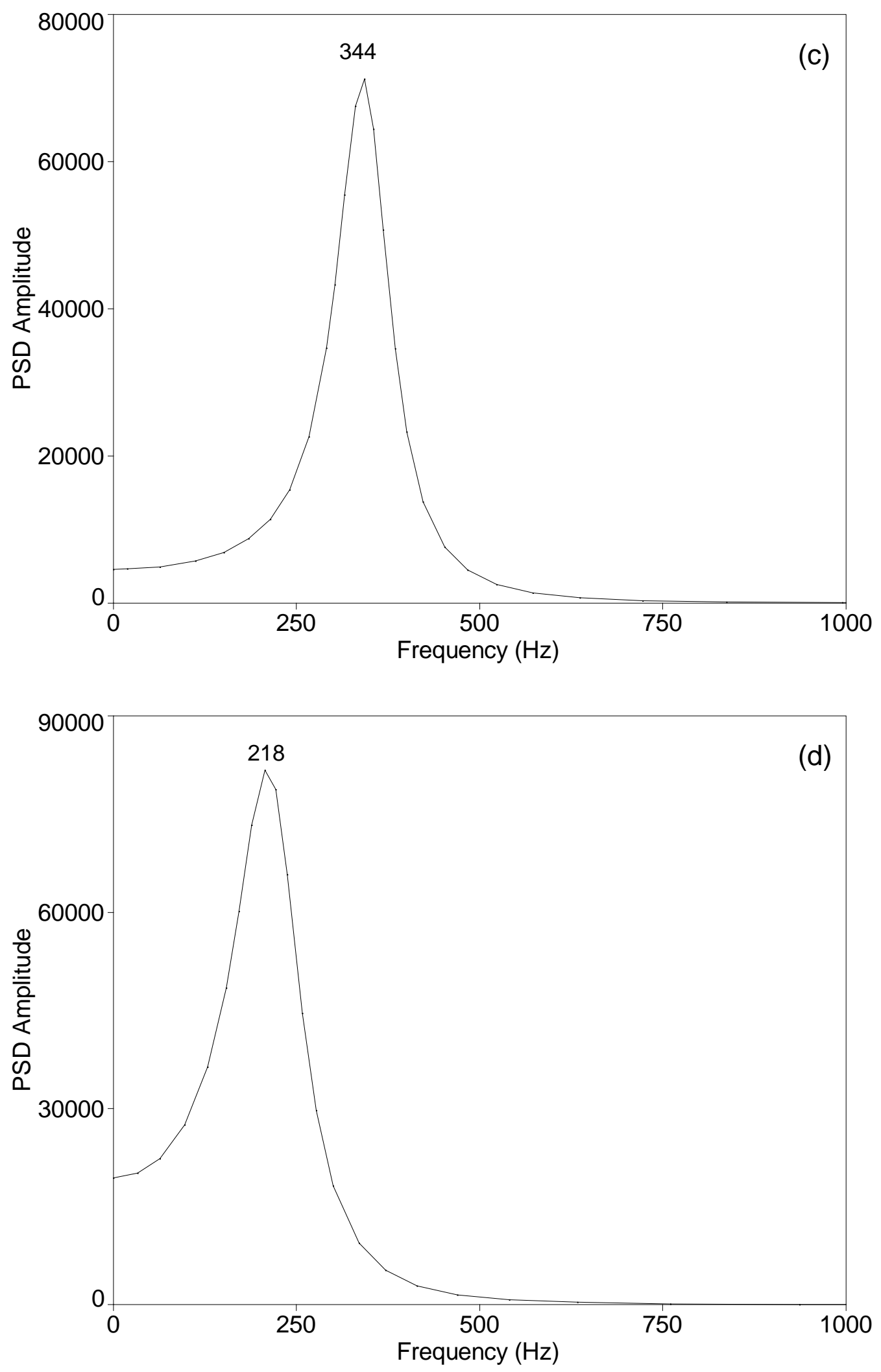

Figure 11 (continued over) 

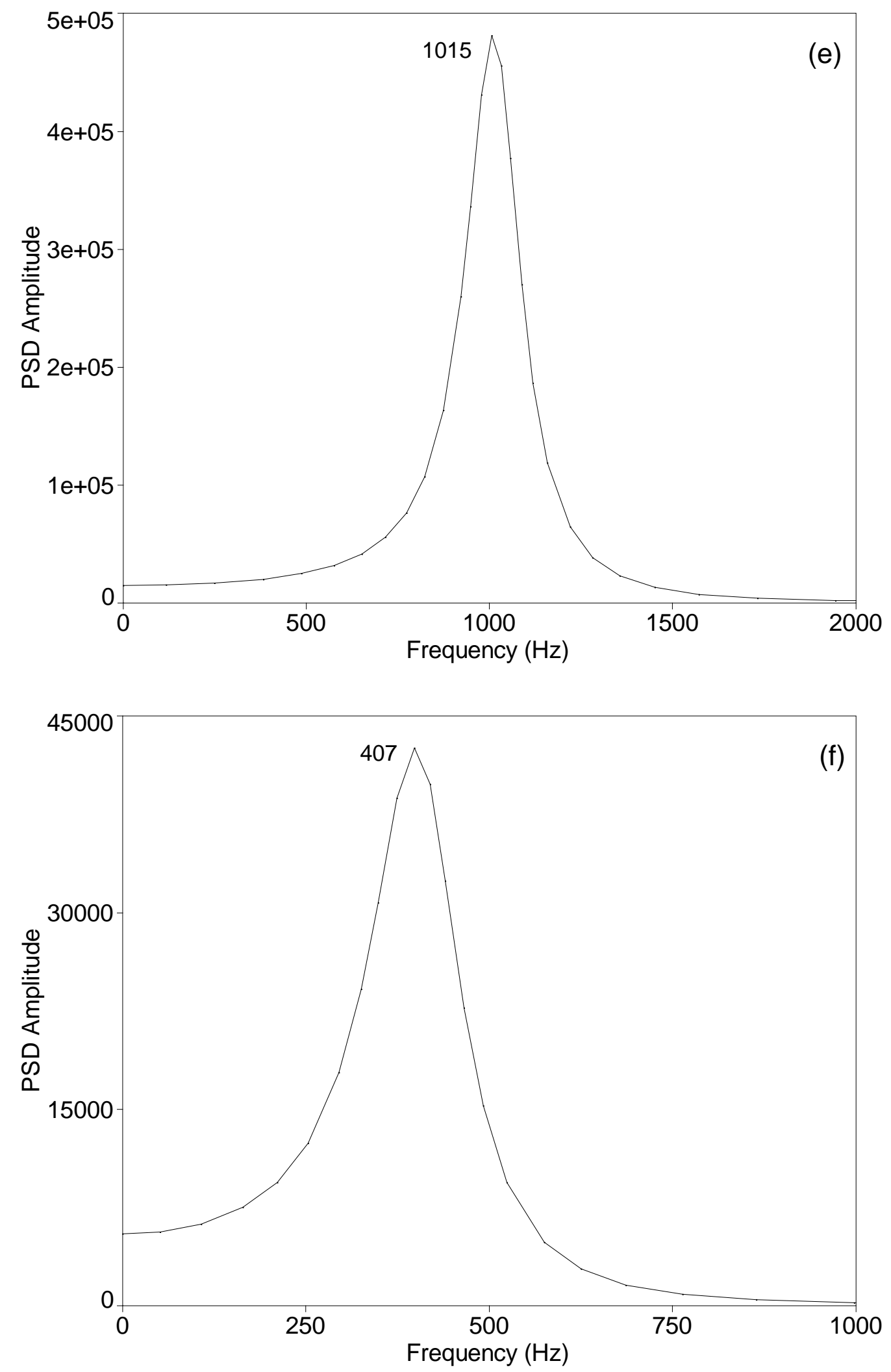

Figure 11 (continued over) 


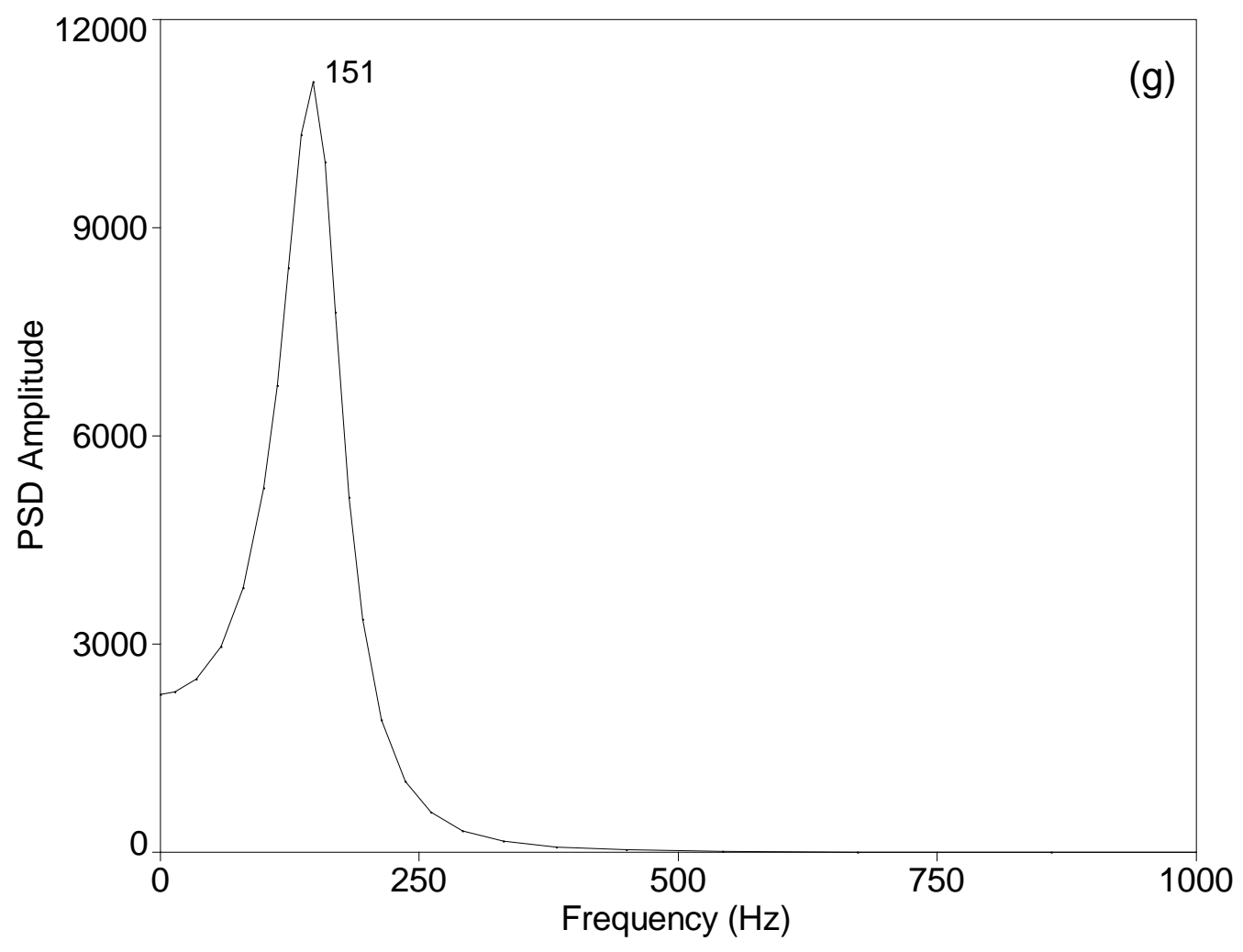

Figure 11: AR Spectra of $\ddot{\varphi}$ for (a) $1^{\text {st }}$ Gear, (b) $2^{\text {nd }}$ Gear, (c) $3^{\text {rd }}$ Gear, (d) $4^{\text {th }}$ Gear, (e) $5^{\text {th }}$ Gear, (f) $6^{\text {th }}$ Gear and (g) Reverse Gear. 

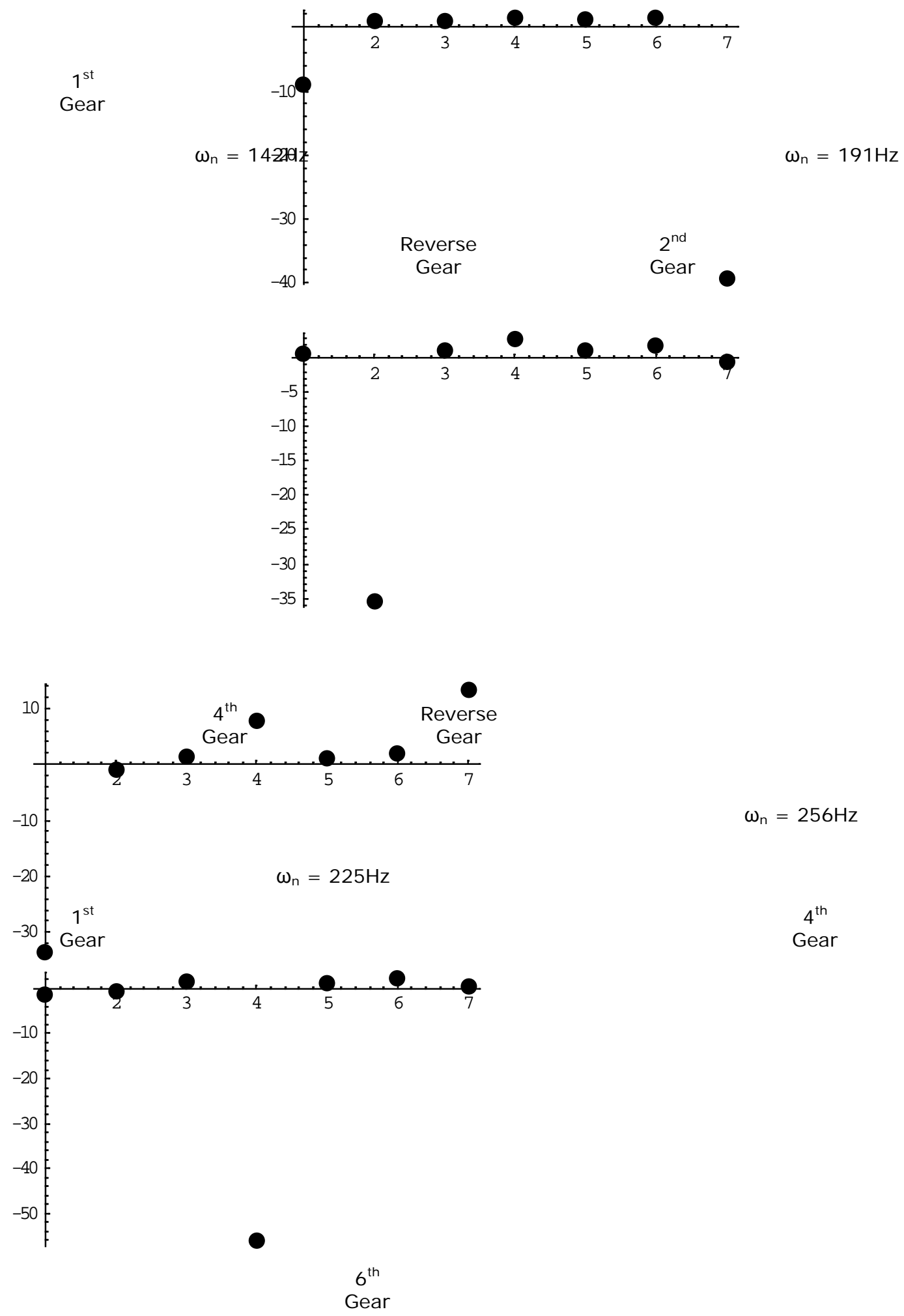


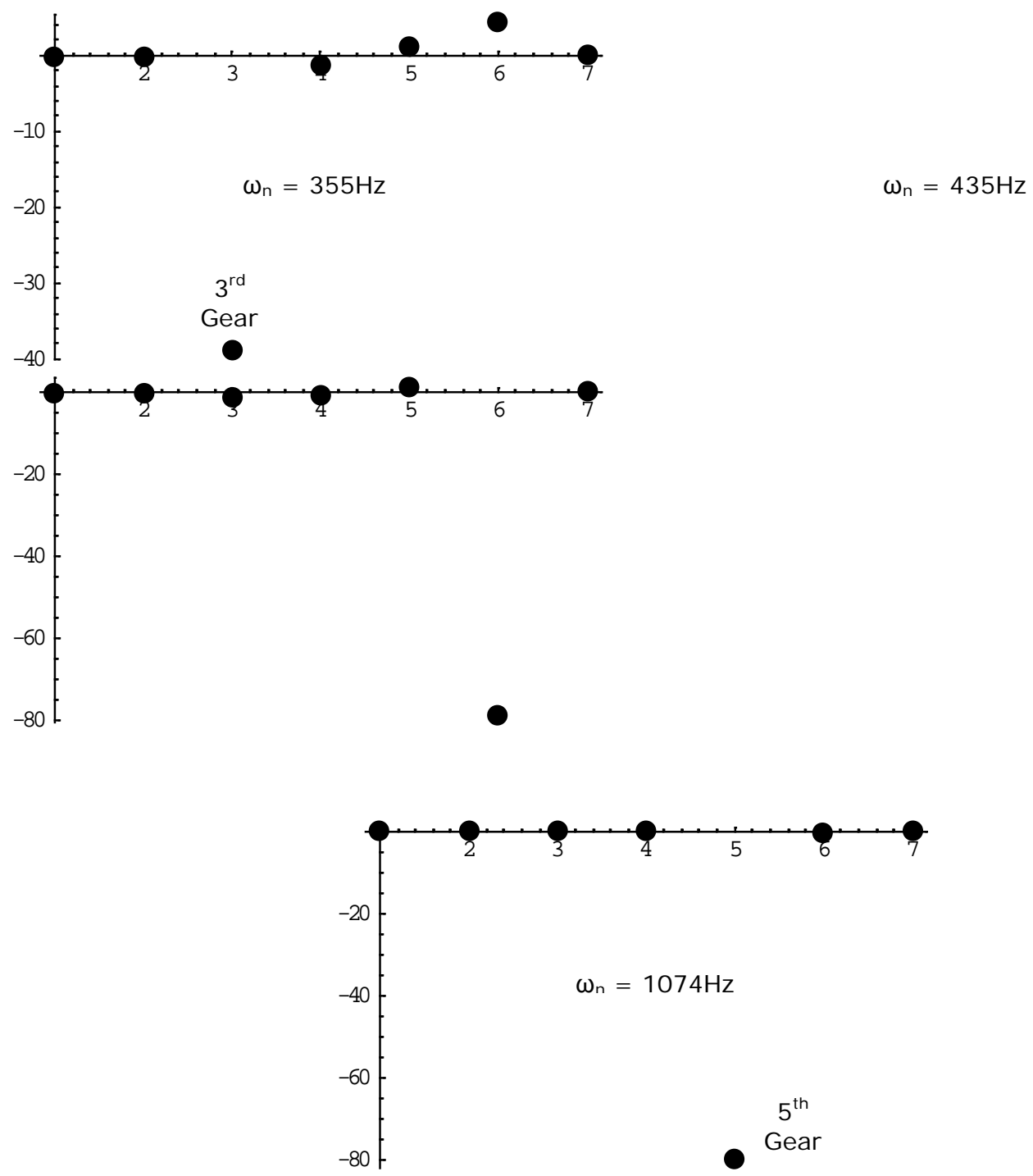

$6^{\text {th }}$

Figure 12: Natural Frequencies and Mode Shapes of the Linearised System Vertical axes in all figures refers to the predicted amplitude of normalised modes 

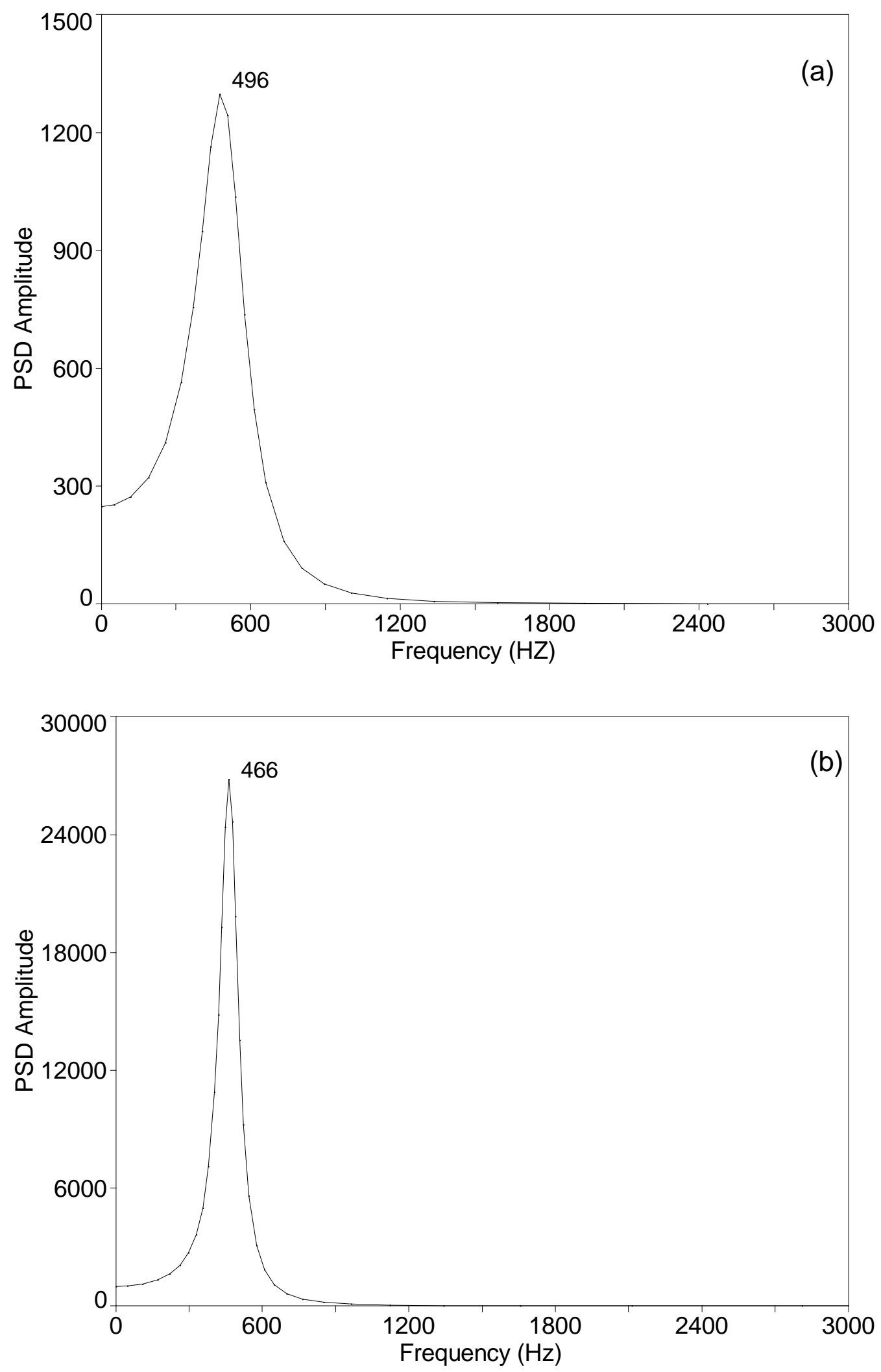

Figure 13 (continued over) 

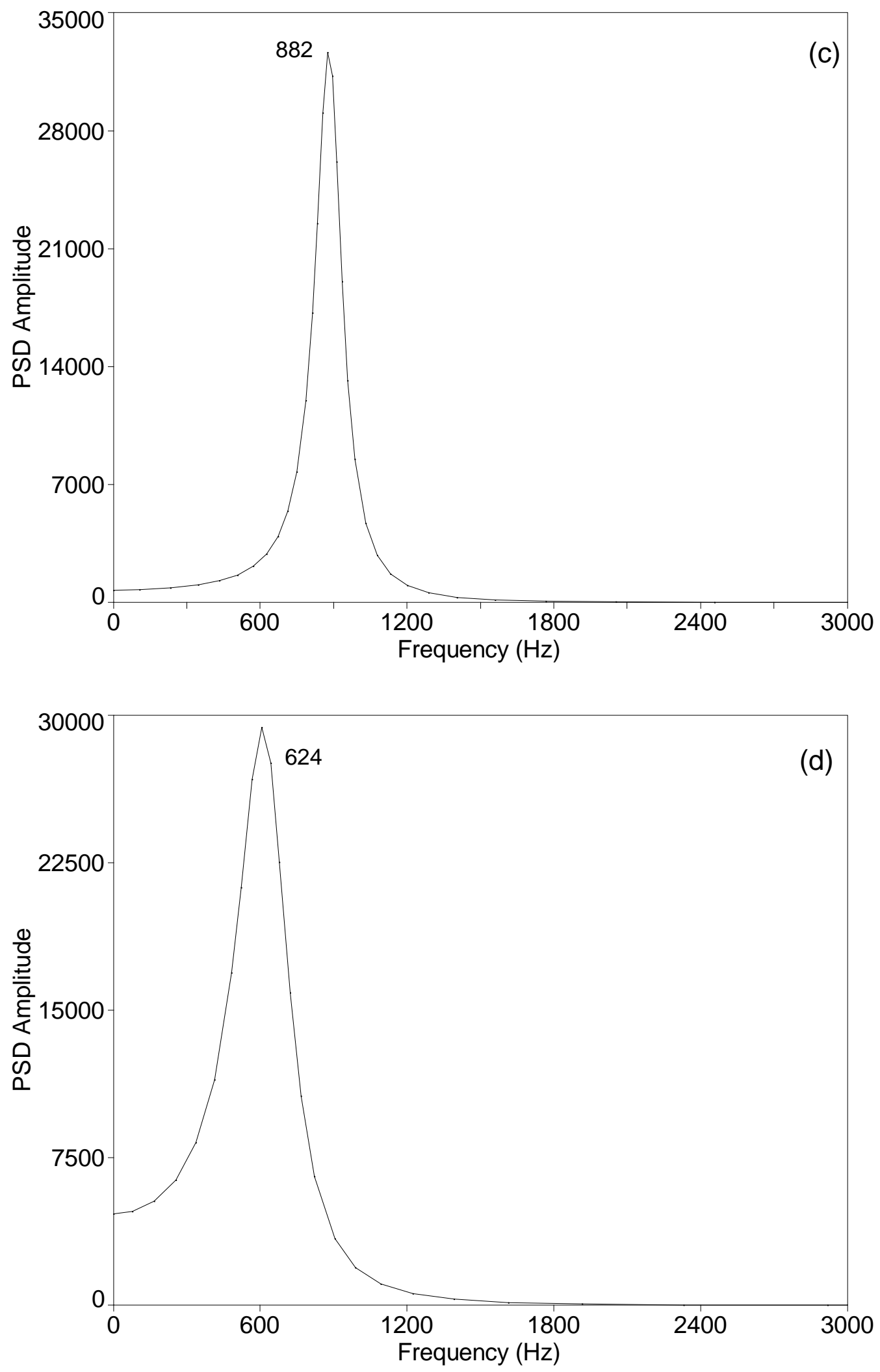

Figure 13 (continued over) 

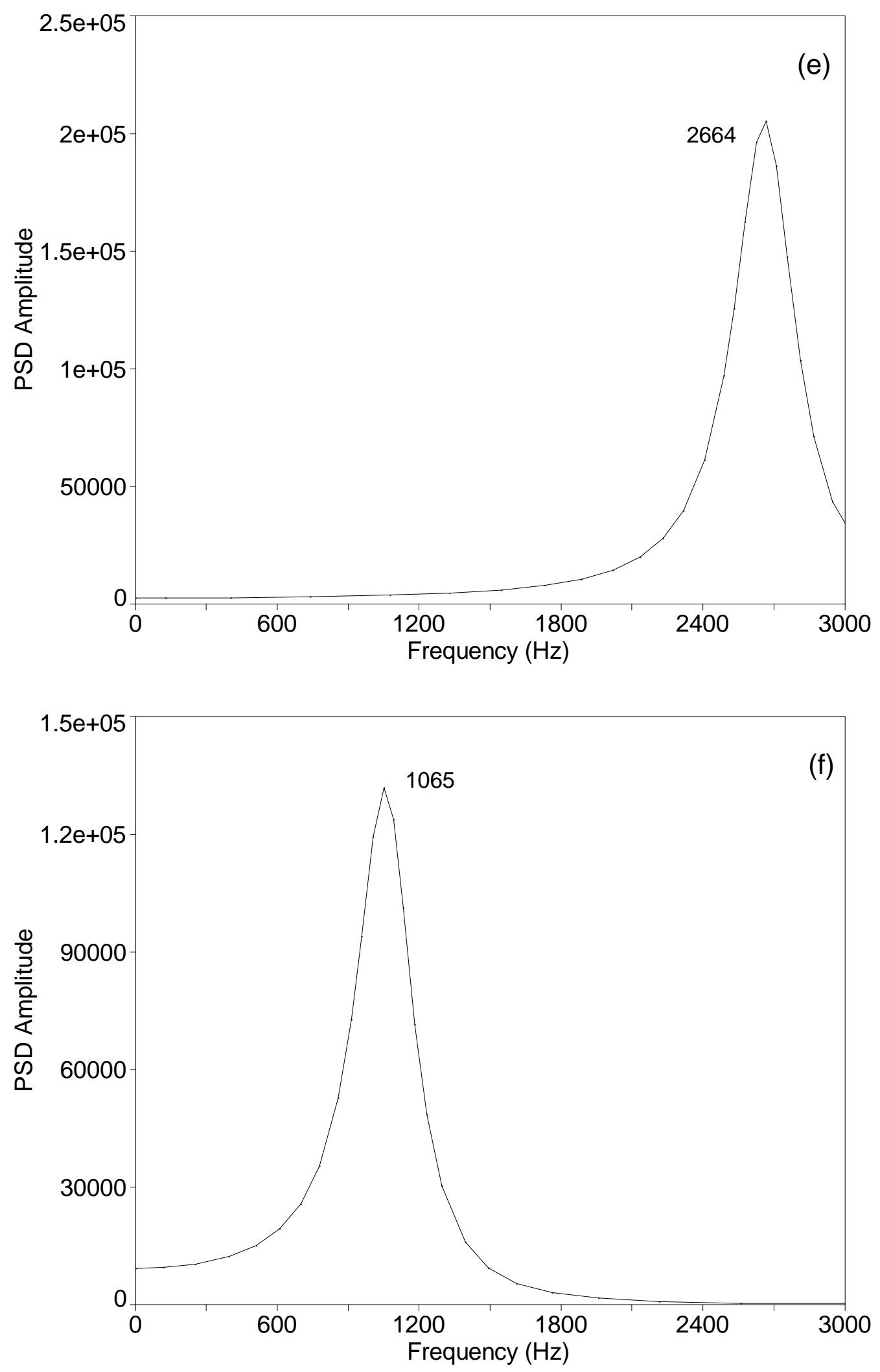

Figure 13 (continued over) 


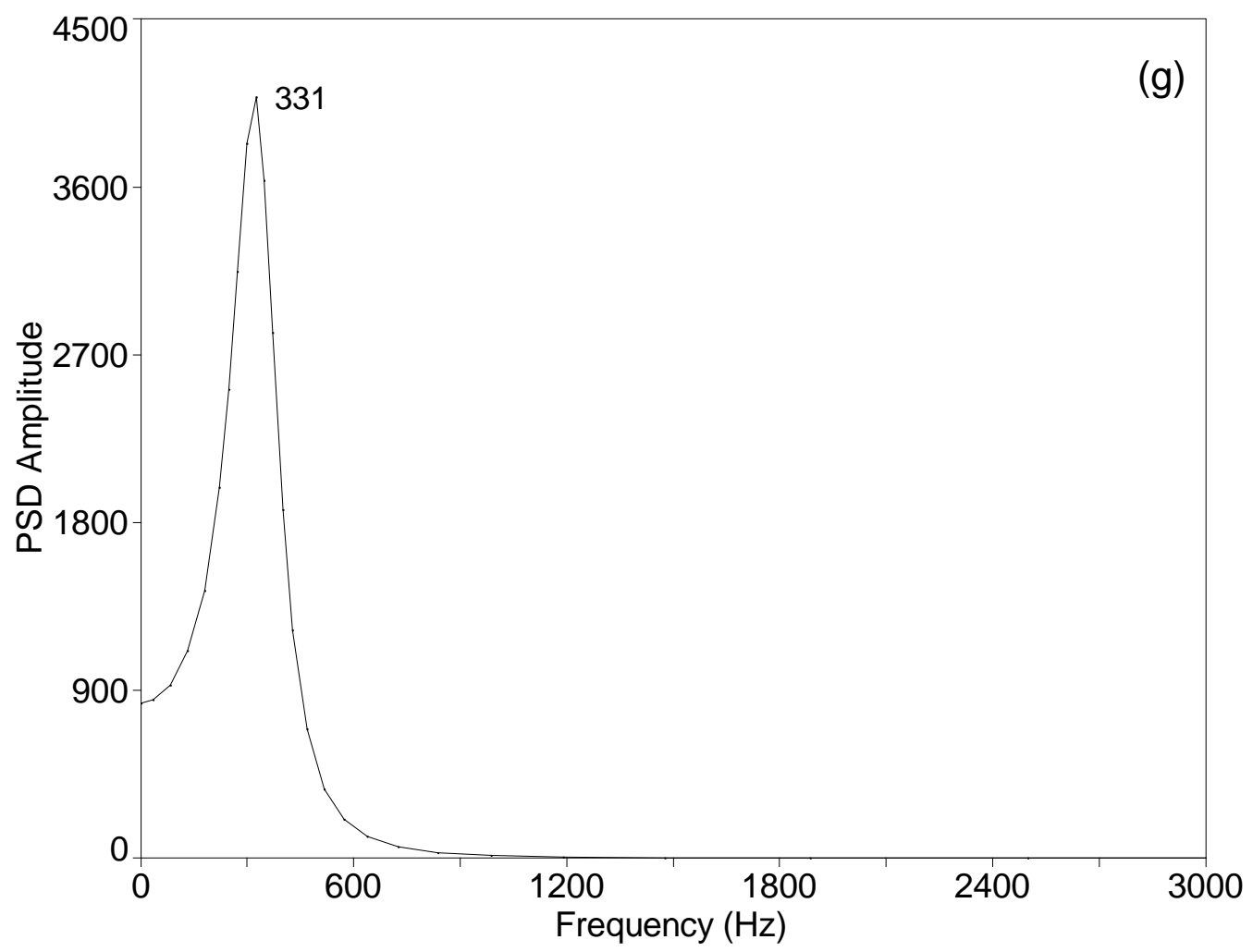

Figure 13: AR Spectra of $\ddot{\varphi}$, corresponding to $20^{\circ} \mathrm{C}$ Lubricant Viscosity for (a) $1^{\text {st }}$ Gear, (b) $2^{\text {nd }}$ Gear, (c) $3^{\text {rd }}$ Gear, (d) $4^{\text {th }}$ Gear, (e) $5^{\text {th }}$ Gear, (f) $6^{\text {th }}$ Gear and (g) Reverse Gear. 

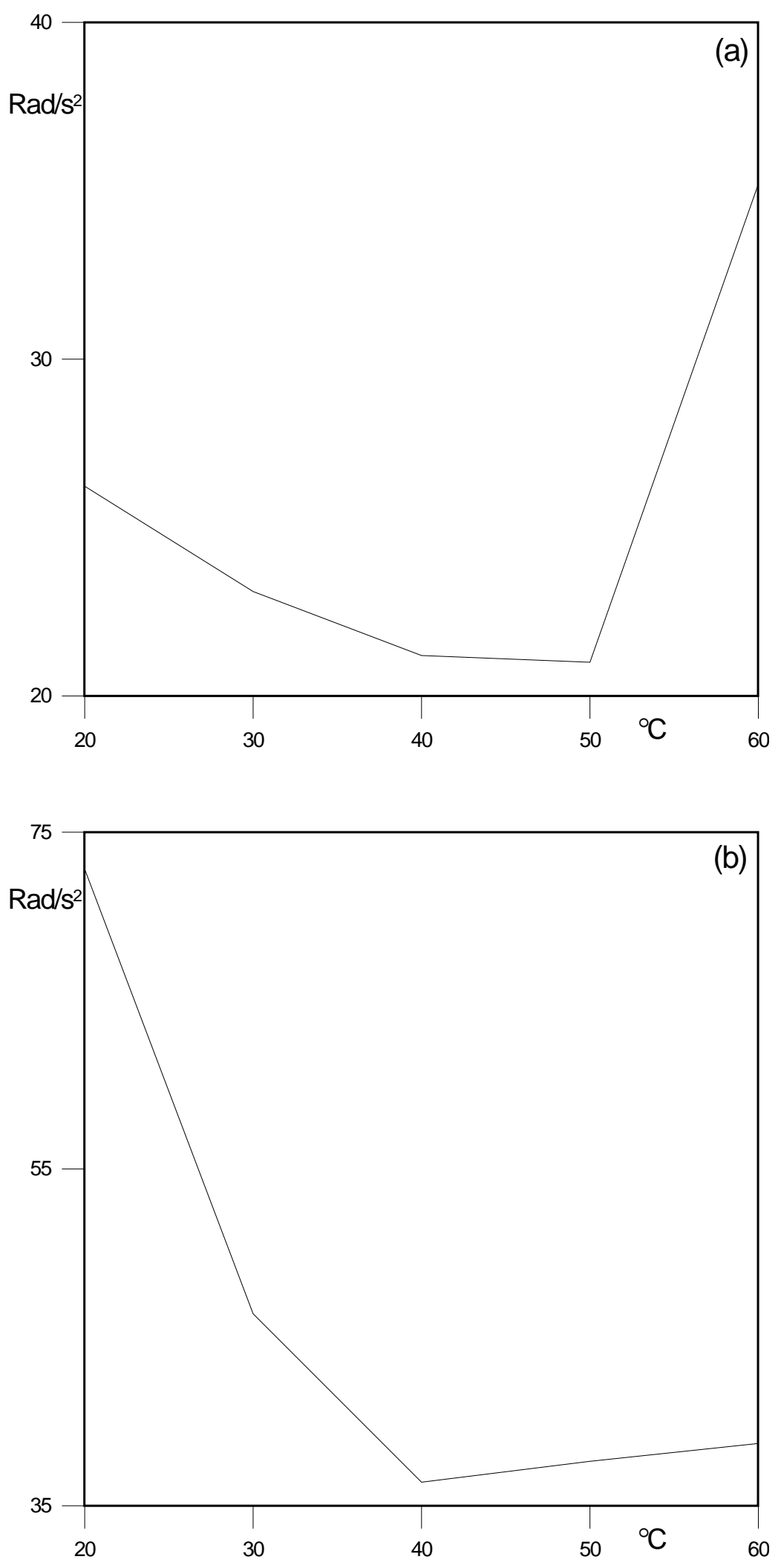

Figure 14 (continued over) 

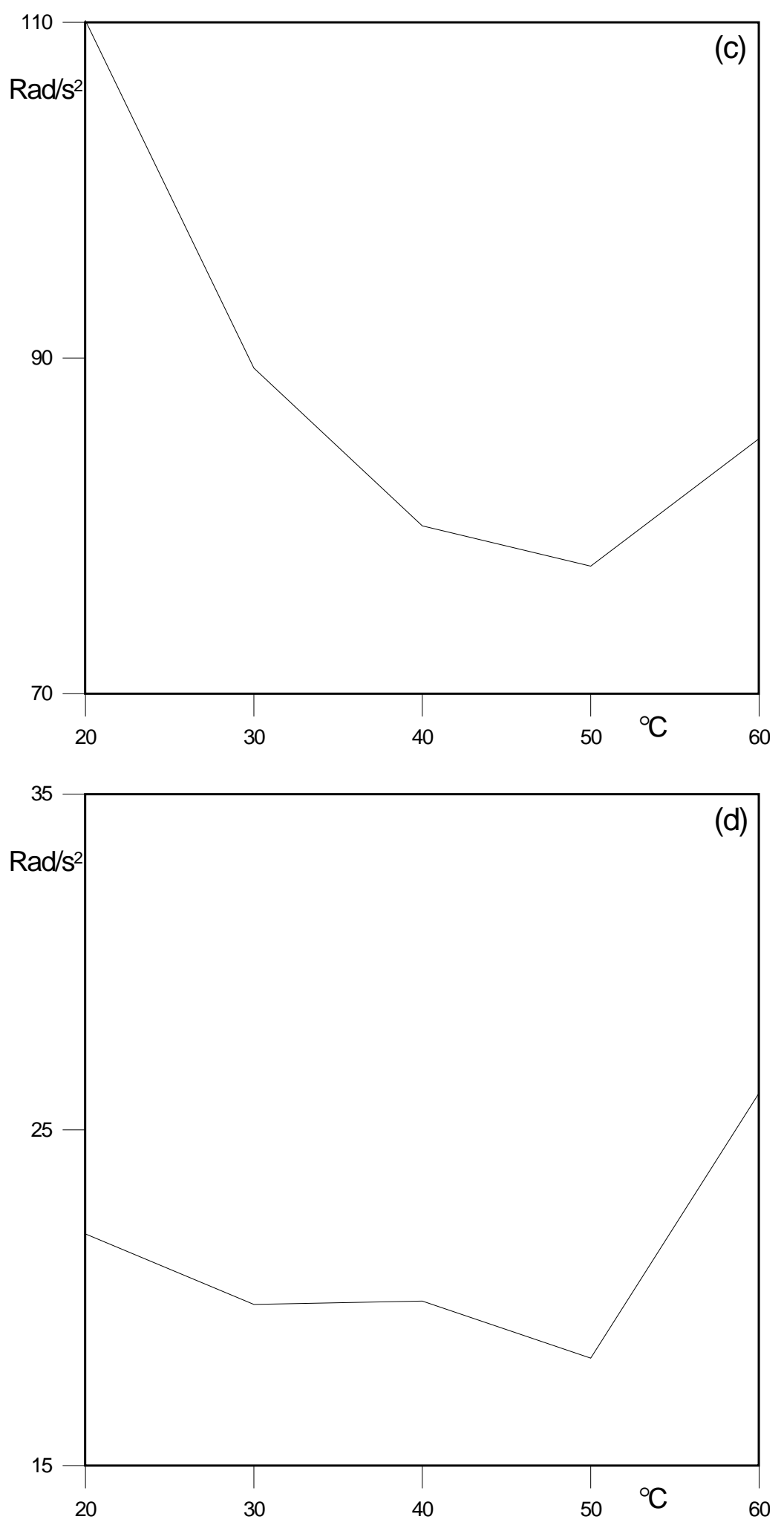

Figure 14: RMS Values of $\ddot{\varphi}$ with respect to Temperature for (a) $1^{\text {st }}$ Gear, (b) $2^{\text {nd }}$ Gear, (c) $4^{\text {th }}$ Gear and (d) Reverse Gear. 


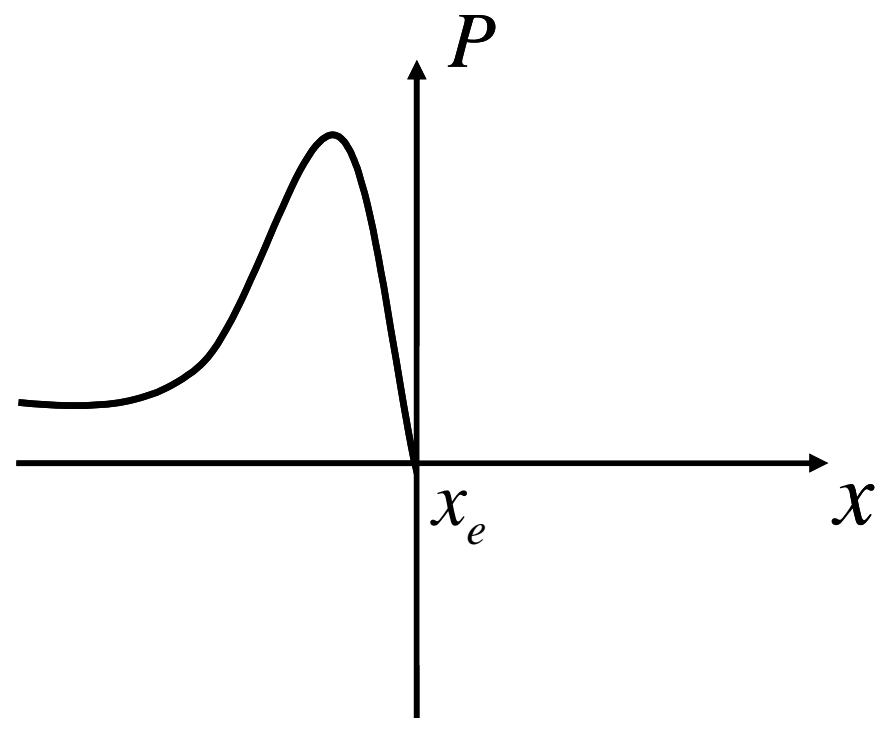

Figure B1: Half-Sommerfeld Conditions

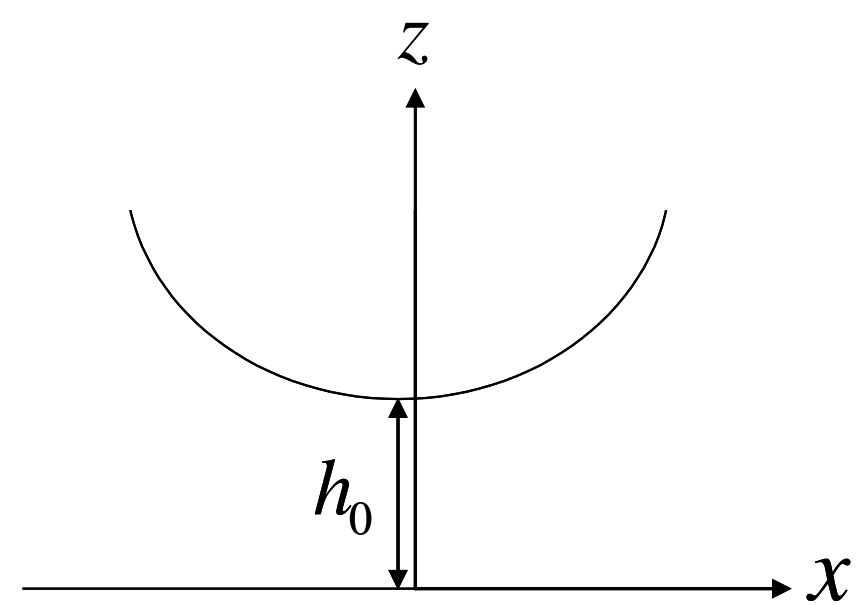

Figure B2: Film Shape in Hydrodynamic Infinite Line Contact 